\title{
Particle fluxes in the deep Eastern Mediterranean basins: the role of ocean vertical velocities
}

\author{
L. Patara ${ }^{1}$, N. Pinardi ${ }^{2}$, C. Corselli ${ }^{3}$, E. Malinverno ${ }^{3}$, M. Tonani ${ }^{4}$, R. Santoleri ${ }^{5}$, and S. Masina ${ }^{1,4}$ \\ ${ }^{1}$ Centro Euro-Mediterraneo per i Cambiamenti Climatici (CMCC), Viale Aldo Moro 44, 40127 Bologna, Italy \\ ${ }^{2}$ Laboratorio SINCEM, Università di Bologna, Via S. Alberto 163, 48100 Ravenna, Italy \\ ${ }^{3}$ Dipartimento di Scienze Geologiche e Geotecnologie, Università Milano-Bicocca, Piazza della Scienza 4, 20126 Milan, Italy \\ ${ }^{4}$ Istituto Nazionale di Geofisica e Vulcanologia (INGV), Viale Aldo Moro 44, 40127 Bologna, Italy \\ ${ }^{5}$ Istituto di Scienze dell'Atmosfera e del Clima - C.N.R., Via del Fosso del Cavaliere 100, 00133 Rome, Italy
}

Received: 25 April 2008 - Published in Biogeosciences Discuss.: 12 August 2008

Revised: 26 January 2009 - Accepted: 10 February 2009 - Published: 6 March 2009

\begin{abstract}
This paper analyzes the relationship between deep sedimentary fluxes and ocean current vertical velocities in an offshore area of the Ionian Sea, the deepest basin of the Eastern Mediterranean Sea. Sediment trap data are collected at $500 \mathrm{~m}$ and $2800 \mathrm{~m}$ depth in two successive moorings covering the period September 1999-May 2001. A tight coupling is observed between the upper and deep traps and the estimated particle sinking rates are more than $200 \mathrm{~m} \mathrm{day}^{-1}$. The current vertical velocity field is computed from a $1 / 16^{\circ} \times 1 / 16^{\circ}$ Ocean General Circulation Model simulation and from the wind stress curl. Current vertical velocities are larger and more variable than Ekman vertical velocities, yet the general patterns are alike. Current vertical velocities are generally smaller than $1 \mathrm{~m} \mathrm{day}^{-1}$ : we therefore exclude a direct effect of downward velocities in determining high sedimentation rates. However we find that upward velocities in the subsurface layers of the water column are positively correlated with deep particle fluxes. We thus hypothesize that upwelling would produce an increase in upper ocean nutrient levels - thus stimulating primary production and grazing - a few weeks before an enhanced vertical flux is found in the sediment traps. High particle sedimentation rates may be attained by means of rapidly sinking fecal pellets produced by gelatinous macro-zooplankton. Other sedimentation mechanisms, such as dust deposition, are also considered in explaining large pulses of deep particle fluxes. The fast sinking rates estimated in this study might be an evi-
\end{abstract}

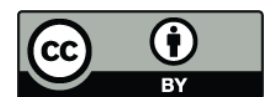

Correspondence to: L. Patara (patara@bo.ingv.it) dence of the efficiency of the biological pump in sequestering organic carbon from the surface layers of the deep Eastern Mediterranean basins.

\section{Introduction}

The Eastern Mediterranean Sea is characterized by an antiestuarine basin scale circulation through the Sicily Channel, with the entrance of surface nutrient-depleted waters and the exiting of nutrient-enriched intermediate waters (MalanotteRizzoli et al., 1997; Pinardi and Masetti, 2000). Superimposed to this large scale circulation pattern, a seasonal wind-forced sub-basin scale circulation is evident (Pinardi and Navarra, 1993; Molcard et al., 2002), with the dominant north-westerly wind component giving a characteristic separation between the southern regions, dominated by anticyclonic motion, and the northern regions, dominated by cyclonic motion (Pinardi et al., 2005). The Eastern Mediterranean general circulation is moreover importantly affected by interannual variability mainly in response to surface fluxes (Korres et al., 2000; Demirov and Pinardi, 2002).

The open areas of the Ionian Sea, which is the deepest basin of the Eastern Mediterranean Sea, are highly oligotrophic, as surface chlorophyll concentrations are generally lower than $0.5 \mathrm{mg} \mathrm{m}^{-3}$ and a deep chlorophyll maximum is found at around 80-100 $\mathrm{m}$ depth (Boldrin et al., 2002; Malinverno et al., 2003; Ignatiades, 2005). The nutricline in the Eastern Mediterranean Sea is normally well below the euphotic layer. Klein et al. (1999) measure in the year 1987 a $300-400 \mathrm{~m}$ deep nutricline in the southeastern Ionian Sea,

Published by Copernicus Publications on behalf of the European Geosciences Union. 
while Ediger and Yilmaz (1996) measure in the Levantine Basin a $600 \mathrm{~m}$ deep nutricline in correspondence of anticyclonic structures. In the Ionian Sea, oligotrophic features increase according to a north-south and west-east gradient (Bricaud et al., 2002; Casotti et al., 2003), in response to different water mass characteristics and possibly circulation patterns. In this oligotrophic region coccolithophores are an important constituent of the phytoplankton assemblage larger than $3 \mu \mathrm{m}$ (Boldrin et al., 2002; Malinverno et al., 2003) and their calcitic remains give a major contribution to the calcium carbonate export to the deep layers (Ziveri et al., 2000).

Organic matter export in the ocean interior - occurring mainly through zooplankton fecal pellets and marine snow particles (Knappertsbusch and Brummer, 1995; Stemmann et al., 2002; Turner, 2002) - is one of the processes maintaining the $\mathrm{CO}_{2}$ partial pressure gradient between surface and deep layers (Sarmiento and Gruber, 2006) and it is therefore involved in the ocean's capacity to absorb atmospheric $\mathrm{CO}_{2}$. Hence it is important to quantify particle sedimentation in the water column and to assess the mechanisms affecting its variability. Particle fluxes may be estimated by means of sediment traps which collect the material sinking through the water column in temporally rotating containers (Honjo, 1996; Buesseler et al., 2007), thus giving a measure of the mass of particles (mg) sinking across the sediment trap surface $\left(\mathrm{m}^{2}\right)$ during a specific time interval (days). Results from sediment traps moored at various depths and geographical settings (Honjo et al., 2008) yield significant variability in particle flux magnitudes and sinking velocities as a consequence of physical and biological processes (Berelson, 2002; Francois et al., 2002; De La Rocha and Passow, 2007; Lutz et al., 2007; Trull et al., 2008).

In oligotrophic open ocean regions particle fluxes are generally very low, and yet they have been observed to strongly react to localized and episodic phenomena such as the passage of mesoscale eddies (Sweeney et al., 2003), elevated zooplankton biomass (Conte et al., 2003; Goldthwait and Steinberg, 2008), and the occurrence of lithogenic dust events (Zuñiga et al., 2008); in addition deep particle fluxes are found to be in some cases decoupled with respect to surface ocean primary production (Buesseler, 1998; Conte et al., 2001; Lutz et al., 2002). However the relevant physical and biological mechanisms controlling particle sedimentation in oligotrophic regions are still to be fully understood.

In this study we investigate the effect of current vertical velocities on particle fluxes measured in the deep Ionian basin. Ocean vertical velocities might influence particle fluxes in two opposite ways: on one hand they could directly increase sedimentation rates through downwelling velocities; on the other hand they could produce, via upwelling velocities, an indirect effect through an enhancement of nutrient levels and primary productivity in the upper ocean.

Particles are sampled during the period 1999-2001 at the Urania and Bannock stations - located in the open southeastern Ionian Sea - by means of sediment traps moored at $500 \mathrm{~m}$ and $2800 \mathrm{~m}$ depth. We analyze total particle flux, i.e. the flux of all sinking particles, and total coccolith flux, i.e. the flux of the calcitic plates constituting the coccolithophore external shell.

Ekman vertical velocities calculated from the wind stress curl were used in previous studies as a proxy of the current vertical velocities and a relation with biological patterns was found (Agostini and Bakun, 2002). However biogeochemical processes and vertical particle fluxes are affected by mesoscale features (McGillicuddy et al., 1999; Sweeney et al., 2003), which are pervasive in the eastern Mediterranean Sea (Robinson et al., 1987) but might not be correctly represented by the large scale Ekman vertical velocities.

Current vertical velocities are difficult to directly measure because of their extremely low values, which are commonly less than $1 \mathrm{~m} \mathrm{day}^{-1}$. We therefore analyze vertical velocities simulated with a $1 / 16^{\circ} \times 1 / 16^{\circ}$ Ocean General Circulation Model (OGCM) for the years 1999-2001. The OGCM vertical velocities are compared with the wind induced Ekman vertical velocities in order to verify the consistency between the two fields. The OGCM vertical velocities are then correlated with particle fluxes from sediment traps.

The paper is organized as follows: Sect. 2 gives some details regarding the particle flux observations and the computation of Ekman and current vertical velocity fields. Section 3 investigates the main results of this work, concentrating on the effect of ocean vertical velocities on particle fluxes measured at the studied sites. In Sect. 4 we discuss the major findings and in Sect. 5 we give a few concluding remarks.

\section{Methods}

\subsection{Particle flux data from sediment traps}

Particle flux data analyzed in this work were collected by means of conical Technicap PPS5/2 sediment traps deployed at $500 \mathrm{~m}$ and $2800 \mathrm{~m}$ depth in two offshore sites located in the southeastern Ionian Sea, the Urania and Bannock stations (Fig. 1). Sediment traps are equipped with 24 polypropylene bottles, have a $1 \mathrm{~m}^{2}$ collection area, measure $2.3 \mathrm{~m}$ height and have an aspect ratio equal to 6.25. The sediment trap time series cover the period 15 September 1999-9 May 2001 in two successive moorings, the first one from 15 September 1999 to 13 May 2000 (hereafter referred to as Mooring 1), the second one from 30 May 2000 to 9 May 2001 (hereafter referred to as Mooring 2). The sampling frequency varies between 10 days for Mooring 1 and 15 days for Mooring 2 .

Soon after recovery, swimmers were removed from the samples by hand picking under a stereoscope with fine tweezers and samples were splitted on board in 8 aliquots using a pneumatic splitter. One aliquot was further splitted into additional sample fractions by means of a rotary splitter. Of these fractions one was filtered on a pre-weighted cellulose acetate filter, dried and then weighted. The measure of total 


\section{Ionian Sea bathymetry}

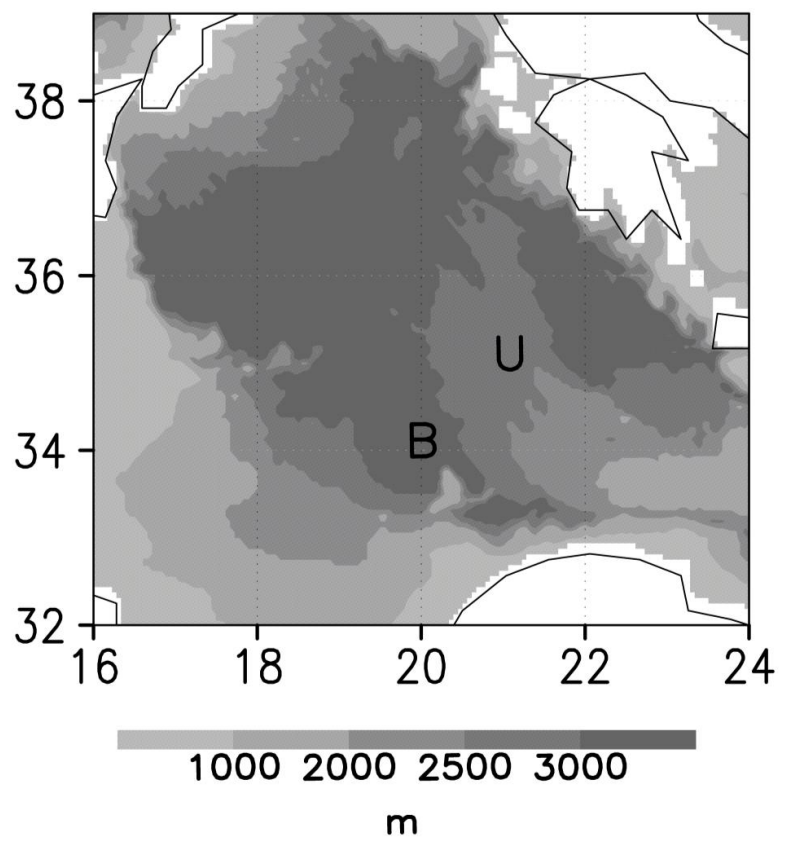

Fig. 1. Ionian Sea bathymetry and sediment trap mooring sites. $\mathrm{U}=$ Urania station (latitude $35^{\circ} 2^{\prime} \mathrm{N}$, longitude $21^{\circ} 2^{\prime} \mathrm{E}$ ), $\mathrm{B}=$ Bannock station (latitude $34^{\circ} 2^{\prime} \mathrm{N}$, longitude $20^{\circ} \mathrm{E}$ ).

particle flux in units of $\mathrm{mg} \mathrm{m}^{-2}$ day $^{-1}$ was then calculated by knowing the sample fraction weight, the sediment trap aperture area, and the sampling frequency. Another fraction, intended for coccolith analysis, was processed following the method of Bairbakhish et al. (1999) in order to remove organic matter and disaggregate particles. Samples were then filtered onto a millipore cellulose acetate filter $(0.45 \mu \mathrm{m}$ pore size, $47 \mathrm{~mm}$ diameter), oven dried at $40^{\circ} \mathrm{C}$ and stored in plastic petri dishes. A portion of each filter was mounted on a glass slide and analyzed along radial transects from the centre to the edge using a polarized light Olympus microscope (LM) at 1250 magnification. Coccolith count of major species was performed on areas of 0.2 to $5 \mathrm{~mm}^{2}$, depending on coccolith concentration on the filter, whereas minor and rare species were counted on areas of 1 to $10 \mathrm{~mm}^{2}$. Coccolith flux was calculated according to the following equation:

$F=\frac{N A_{f} S}{a_{f} A_{s t} T}$,

where $F=$ coccolith flux $\left(\mathrm{nC} \mathrm{m}^{-2} \mathrm{day}^{-1}\right), N=$ number of counted specimens (nC), $A_{f}=$ filter area $\left(\mathrm{mm}^{2}\right), S=$ split factor, $a_{f}=$ investigated filter area $\left(\mathrm{mm}^{2}\right), A_{s t}=$ sediment trap aperture area $\left(\mathrm{m}^{2}\right)$ and $T=$ sample collecting interval (days). Because of the utilized sampling procedure, coccolith data represent the contribution from both loose coccoliths and coccospheres disaggregated during sample preparation. Flux
Table 1. Available sediment trap data from the Urania and Bannock sites, where TPF=Total Particle Flux $\left(\mathrm{mg} \mathrm{m}^{-2} \mathrm{day}^{-1}\right)$ and $\mathrm{TCF}=$ Total Coccolith Flux $\left(\mathrm{nC} \mathrm{m}^{-2} \mathrm{day}^{-1}\right)$. Mooring 1=from 15 September 1999 to 13 May 2000 and Mooring 2= from 30 May 2000 to 9 May 2001.

\begin{tabular}{llll}
\hline \multirow{2}{*}{$\begin{array}{l}\text { Sampling } \\
\text { period }\end{array}$} & \multicolumn{2}{c}{ URANIA site } & BANNOCK site \\
& $500 \mathrm{~m}$ depth & 2800 m depth & 2800 m depth \\
\hline Mooring 1 & TPF, TCF & TPF, TCF & TPF \\
Mooring 2 & TPF, TCF & & TPF \\
\hline
\end{tabular}

data at the Urania station are available at both $500 \mathrm{~m}$ and $2800 \mathrm{~m}$ depth for Mooring 1 , and at $500 \mathrm{~m}$ depth for Mooring 2. At the Bannock station only total particle flux at $2800 \mathrm{~m}$ depth is available (see Table 1).

A few technical problems were encountered during the sampling procedures. At the Urania site, a few samples from the Mooring 1 time series collected at $2800 \mathrm{~m}$ depth dissolved in the laboratory after being weighted and before the coccolith count: the total particle flux time series is therefore complete, whereas a few samples are missing from the coccolith flux time series. During the sediment trap recovery of Mooring 1, the last collecting bottle remained open during the ascent through the water column: the last samples of the two time series - at $500 \mathrm{~m}$ depth and at $2800 \mathrm{~m}$ depth may therefore give an overestimated value of the true particle flux. At the Bannock site, the sediment trap rotation mechanism stopped after the 16th temporal interval of Mooring 1, i.e. after 24 February 2000. Particles sinking during the remaining part of the time series (25 February 2000-13 May 2000) were then collected in one single vial during a period of 79 days.

\subsection{Vertical velocities calculation}

The model used in this study is derived from the OPA code (Madec et al., 1998), it has a horizontal resolution of $1 / 16^{\circ} \times 1 / 16^{\circ}$ (corresponding to a grid spacing of approximately $6 \mathrm{~km}$ ) and a vertical z-level step-wise discretization with 72 unevenly spaced levels. Vertical resolution is enhanced in the upper layers and gradually decreases with depth (Tonani et al., 2008).

The current vertical velocity field is computed as a diagnostic variable according to the continuity equation for an incompressible fluid:

$$
w(z)=w(-H)-\int_{-H}^{z}\left(\frac{\partial u}{\partial x}+\frac{\partial v}{\partial y}\right) d z^{\prime}
$$

where $u$ and $v$ are the horizontal velocity components, $w$ is the vertical velocity component and $-H$ is the bottom depth. 
The kinematic bottom boundary condition for vertical velocity can be expressed as:

$w(-H)=-\boldsymbol{U}_{\boldsymbol{h}} \cdot \nabla_{\boldsymbol{h}} H$,

where $\boldsymbol{U}_{\boldsymbol{h}}=(u, v)$ and $\boldsymbol{\nabla}_{\boldsymbol{h}}=(\partial / \partial x, \partial / \partial y)$. Because of the bottom topography discretization used, $\nabla_{h} H$ is equal to zero, thus vertical velocity at the ocean bottom will also be zero. A discussion over the vertical velocity representation at the ocean bottom in z-level models may be found in Pacanowski and Gnanadesikan (1998).

We compare current vertical velocity computed with Eq. (2) with Ekman vertical velocity, calculated as a function of the curl of the wind stress $\boldsymbol{\tau}=\left(\tau_{x}, \tau_{y}\right)$ according to:

$w_{E}\left(x, y, \delta_{E}\right)=\frac{1}{\rho_{o} f}\left(\boldsymbol{k} \cdot \nabla_{\boldsymbol{h}} \times \boldsymbol{\tau}+\frac{\beta \tau_{x}}{f}\right)$,

where $w_{E}$ is the Ekman vertical velocity, $\boldsymbol{\tau}$ is computed from ECMWF winds using a bulk formula as reported in Tonani et al. (2008), $\rho_{0}$ is the average seawater density taken as $1029 \mathrm{~kg} \mathrm{~m}^{-3}$, and $f$ is the Coriolis parameter. The $\beta$ parameter, i.e. the meridional gradient of $f$, is computed as $\beta=2 \Omega \cos \theta / r$, where $r$ and $\Omega$ are the Earth radius and angular velocity, and $\theta$ is the latitude.

Ekman vertical velocities are defined at the Ekman layer depth $\delta_{E}$, which is the e-folding depth of the wind-induced currents. For the Mediterranean Sea $\delta_{E}$ is generally between $20 \mathrm{~m}$ and $40 \mathrm{~m}$. Such an estimate is calculated using the scaling formula $\delta_{E}=\pi \sqrt{2 A_{v} /|f|}$ (Pond and Pickard, 1983), where $A_{v}$ is the vertical eddy coefficient for momentum, calculated in the model as a function of the Richardson number (Tonani et al., 2008) and normally variable between $10^{-2}$ and $10^{-3} \mathrm{~m}^{2} \mathrm{~s}^{-1}$.

We use daily wind stress fields for the years 1999-2001 to compute Ekman vertical velocities and daily current velocity fields of the model output to compute current vertical velocities. The comparison between the two fields is done on a monthly basis at $30 \mathrm{~m}$ depth. The comparison between the vertical velocity fields and the particle flux time series is done by averaging the former fields on the same time intervals of the sediment traps, i.e. 10 days for Mooring 1 and 15 days for Mooring 2.

Current vertical velocity values are vertically averaged between $100 \mathrm{~m}$ and $600 \mathrm{~m}$ depth, which allows for the surface high frequency signals to be neglected and is deep enough for the nutricline depth to be included at all seasons (Ediger and Yilmaz, 1996; Klein et al., 1999). The vertical velocity field is then horizontally averaged on six areas of increasing dimensions around the station coordinates, with the aim of assessing how the spatial heterogeneity of vertical velocities affects correlations with particle flux data.

Spearman rank correlation coefficients between current vertical velocities and particle fluxes are calculated. We use this non-parametric method because particle flux time series

\section{Year 1999}

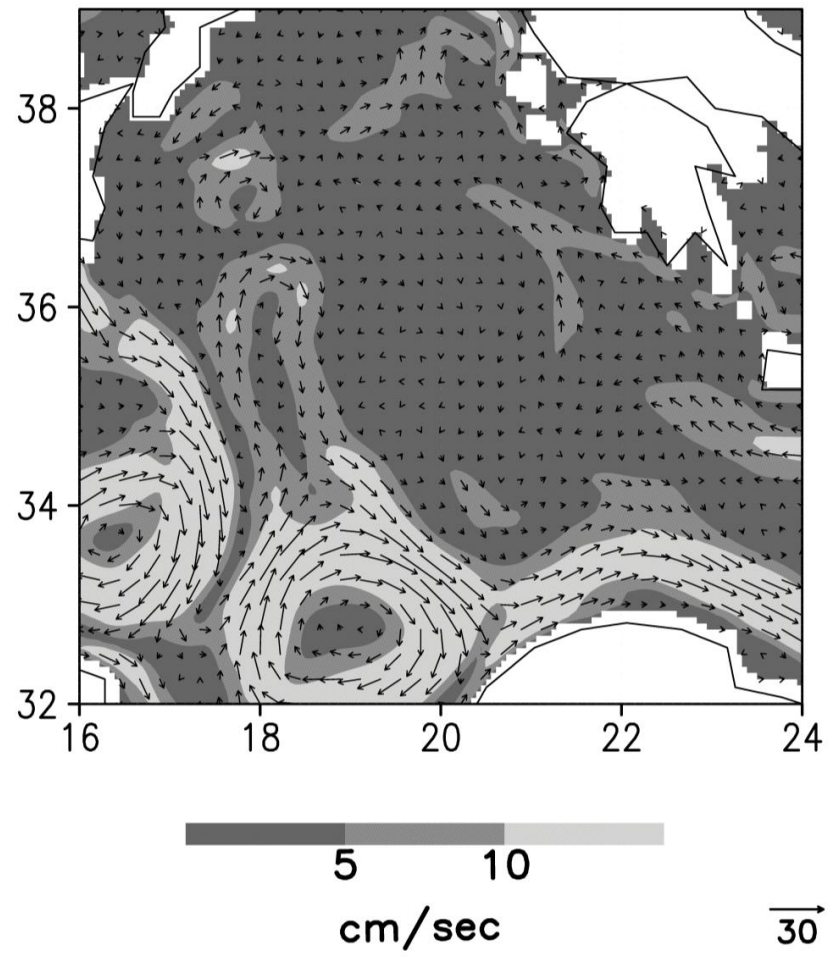

Fig. 2. Simulated current horizontal velocities $\left(\mathrm{cm} \mathrm{s}^{-1}\right)$ in the Ionian Sea at $30 \mathrm{~m}$ depth averaged over the year 1999. The arrow on the bottom-right of the panel indicates the $30 \mathrm{~cm} \mathrm{~s}^{-1}$ velocity.

do not fit a normal distribution. However we would like to mention that the use of Pearson correlation coefficients yields very similar results. Correlations are calculated both without a time lag ("0 lag" case) and with particle fluxes shifted of one ("1 lag" case) and two ("2 lags" case) sediment trap rotation intervals with respect to current vertical velocities. The "1 lag" case corresponds to a shift of 10 days for Mooring 1 and of 15 days for Mooring 2, whereas the "2 lags" case corresponds to a shift of 20 days for Mooring 1 and of 30 days for Mooring 2. The computation of lagged correlations is aimed at assessing the delayed effects of ocean vertical velocities on particle fluxes.

\section{Results}

\subsection{Surface circulation in the Ionian Sea}

In Fig. 2 we show an annual average for the year 1999 of the horizontal circulation at $30 \mathrm{~m}$ depth simulated with the OGCM described in Sect. 2.2. Modified Atlantic Water entering the Sicily Strait flows mainly eastwards towards the Levantine Sea and separates the Ionian Basin in two regions characterized by an anticyclonic circulation to the south and 


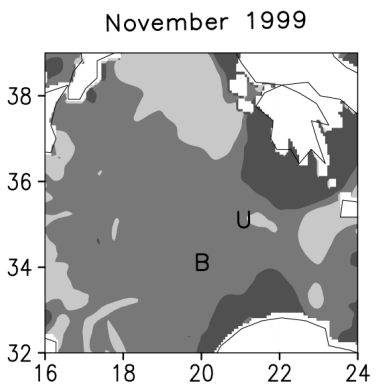

$-0.1 \quad 0.1$
$\mathrm{~m} / \mathrm{day}$

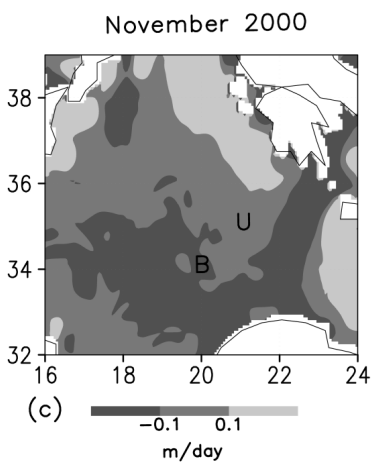

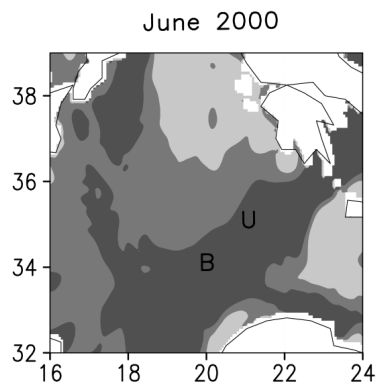

(b)

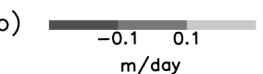

$\mathrm{m} /$ day

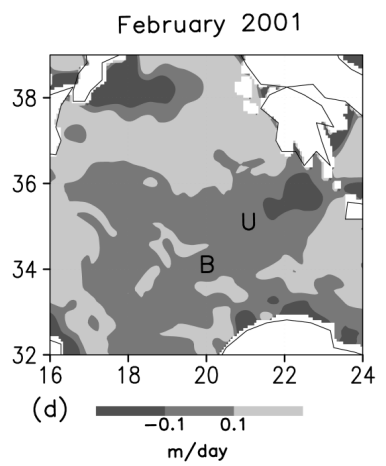

Fig. 3. Ekman vertical velocities $\left(\mathrm{mday}^{-1}\right)$ in the Ionian Sea in (a) November 1999, (b) June 2000, (c) November 2000, and (d) February 2001. In letters we indicate the positions of the Urania (U) and Bannock (B) stations.

a weak and prevailingly cyclonic circulation to the north. A large meander of the Modified Atlantic Water current, called the Atlantic Ionian Stream (Robinson et al., 1999), is present in the Ionian Sea around $34^{\circ} \mathrm{N}$ with an anticyclonic curvature and a detached anticyclonic eddy to the north (up to $37^{\circ} \mathrm{N}$ ).

The Ionian Sea was affected in the late 80 s by an intensification and northward extension of the anticyclonic circulation (Malanotte-Rizzoli et al., 1999; Demirov and Pinardi, 2002). This circulation change, which is an aspect of the widespread phenomenon known as the Eastern Mediterranean Transient, appears to have recovered since the late 90s (Manca et al., 2003). The weak but cyclonic circulation north of $35^{\circ} \mathrm{N}$ and the large but limited in extent anticyclonic meander and northward eddy are signatures of such change, which our model succeeds to capture.

\subsection{Vertical velocities in the Ionian Sea}

The Ekman Vertical Velocity field (hereafter referred to as EVV) calculated according to Eq. (4), is depicted in Fig. 3 for the months of November 1999, June and November 2000, and February 2001, which are months overlapping with sediment trap data. EVVs have values between -0.1 and $0.1 \mathrm{~m} \mathrm{day}^{-1}$ on large portions of the Ionian basin and exhibit a typical large scale structure consistent with the large
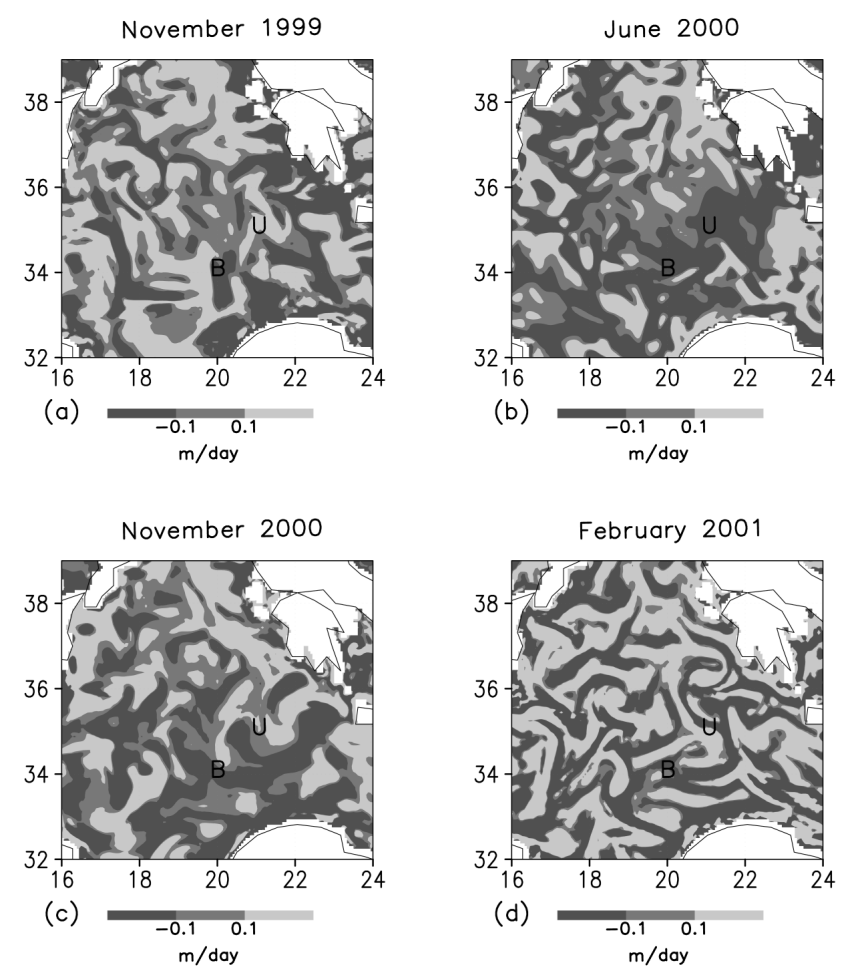

Fig. 4. Simulated current vertical velocities $\left(\mathrm{mday}^{-1}\right)$ in the Ionian Sea at $30 \mathrm{~m}$ depth in (a) November 1999, (b) June 2000, (c) November 2000, and (d) February 2001. In letters we indicate the positions of the Urania (U) and Bannock (B) stations.

scale wind field. Positive values, i.e. upward EVVs, are prevalently found in the northern part of the Ionian basin, while the southeastern regions are typically characterized by negative values, i.e. downward EVVs. Seasonal and interannual variability is moreover evident: in February 2001 the Ionian Basin exhibits the largest areas with upward EVV, while June and November 2000 are characterized by prevailingly downward EVVs. The upward EVVs are then stronger in the northern part of the basin and in the winter season.

The Current Vertical Velocity field (hereafter referred to as CVV), calculated according to Eq. (2), is depicted in Fig. 4 at $30 \mathrm{~m}$ depth for the months of November 1999, June and November 2000, and February 2001. The CVV field is noisier with respect to the EVV field and values generally exceed $0.1 \mathrm{~m} \mathrm{day}^{-1}$ in absolute value. This is due to the intense mesoscale eddy field that modulates the Ekman vertical velocities. Consistently with the EVV field, a north-south gradient in the CVV sign and a large seasonal variability are evident, with a broadening of the areas of downward CVVs during the summer months and of the areas of upward CVVs during the winter months. The comparison between the CVV field in November 1999 and in November 2000 reveals significant interannual variability, in agreement with the EVV field. 

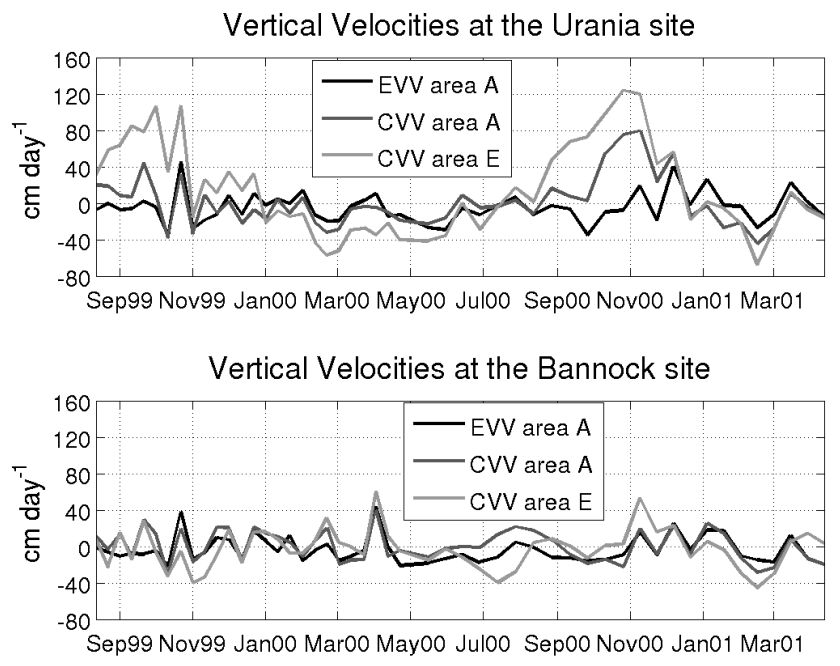

Fig. 5. Ocean vertical velocities $\left(\mathrm{cm} \mathrm{day}^{-1}\right)$ at the Urania (top) and Bannock (bottom) sites, where EVV=Ekman Vertical Velocity computed from the wind stress curl, and CVV=simulated Current Vertical Velocity, vertically averaged between $100 \mathrm{~m}$ and $600 \mathrm{~m}$ depth. EVVs are horizontally averaged over an area of $145 \mathrm{~km}$ side (area A); CVVs are horizontally averaged over areas of $85 \mathrm{~km}$ side (area E) and $145 \mathrm{~km}$ side (area A). The tick marks on the $\mathrm{x}$-axis indicate the 15 th day of each month.

In Fig. 5 we show time series at the Urania and Bannock sites of EVV, horizontally averaged over an area of $145 \mathrm{~km}$ side (area A), and of CVV, vertically averaged between $100 \mathrm{~m}$ and $600 \mathrm{~m}$ depth and horizontally averaged over areas of $145 \mathrm{~km}$ side (area A) and of $85 \mathrm{~km}$ side (area E). EVV and CVV exhibit in many cases synchronous peaks, thus suggesting a relevant role of the wind stress curl field in modulating the seasonal variability of ocean vertical velocity. CVV, in particular when averaged over the smaller area $\mathrm{E}$, is however much larger in amplitude with respect to EVV, thus indicating that ocean dynamics enhances the atmospheric forcing and translates it into smaller scale motions. Due to the spatial and temporal variability of CVV, the Urania and Bannock stations despite their vicinity are characterized by different circulation regimes. This variability does not appear to be correctly captured by the large scale EVV field, which we therefore do not believe suitable for the computation of correlations with sediment trap data.

\subsection{Particle fluxes at the Urania and Bannock stations}

Total Particle Flux (hereafter referred to as TPF) measured at the Urania site is depicted in logarithmic scale in Fig. 6 with a light-gray line; Current Vertical Velocity (CVV), averaged between $100 \mathrm{~m}$ and $600 \mathrm{~m}$ depth and on an area of $85 \mathrm{~km}$ side (area E), is superimposed on the same plot with a dark-gray line.

At $500 \mathrm{~m}$ depth TPF is highest between mid-May 2000 and the beginning of June 2000, when it exceeds
$100 \mathrm{mg} \mathrm{m}^{-2}$ day $^{-1}$. Secondary flux maxima exceeding $25 \mathrm{mg} \mathrm{m}^{-2}$ day $^{-1}$ occur in September-November 1999, at the beginning of March 2000, in November-December 2000 and in April 2001. TPFs lower than $2 \mathrm{mg} \mathrm{m}^{-2} \mathrm{day}^{-1}$ occur throughout the period January-March 2001. At $2800 \mathrm{~m}$ depth TPF is highest in mid-May 2000 with a value exceeding $100 \mathrm{mg} \mathrm{m}^{-2} \mathrm{day}^{-1}$ (we recall however that this value is probably overestimated), whereas secondary flux maxima in excess of $25 \mathrm{mg} \mathrm{m}^{-2}$ day $^{-1}$ occur in the period of September-October 1999. TPF at the Urania site is on average $17 \mathrm{mg} \mathrm{m}^{-2}$ day $^{-1}$ at $500 \mathrm{~m}$ depth (with a standard deviation of $20 \mathrm{mg} \mathrm{m}^{-2} \mathrm{day}^{-1}$ ) and $13 \mathrm{mg} \mathrm{m}^{-2} \mathrm{day}^{-1}$ at $2800 \mathrm{~m}$ depth (with a standard deviation of $12 \mathrm{mg} \mathrm{m}^{-2} \mathrm{day}^{-1}$ ). The large value of the standard deviation indicates that the mean is not a robust estimate of the probability distribution due to the eventful and short time series.

Total Coccolith Flux (hereafter referred to as TCF) measured at the Urania site is depicted in logarithmic scale in Fig. 7 with a light-gray line; Current Vertical Velocity (CVV), averaged between $100 \mathrm{~m}$ and $600 \mathrm{~m}$ depth and on an area of $85 \mathrm{~km}$ side (area $\mathrm{E}$ ), is superimposed on the same plot with a dark-gray line.

TCF at $500 \mathrm{~m}$ depth shows a sporadic peak around $3 \times 10^{9} \mathrm{nC} \mathrm{m}^{-2}$ day $^{-1}$ between mid-May and the beginning of June 2000 and secondary flux maxima in excess of $5 \times 10^{8} \mathrm{nC} \mathrm{m}^{-2} \mathrm{day}^{-1}$ at the end of September 1999 and in March 2000. At $2800 \mathrm{~m}$ depth TCF exhibits the largest values (in excess of $5 \times 10^{8} \mathrm{nC} \mathrm{m}^{-2} \mathrm{day}^{-1}$ ) in the period September-November 1999 and in mid-May 2000 (even though this value is probably overestimated). Microscope visual inspection has revealed no evidence of coccolith dissolution (Malinverno et al., in preparation): this observation is consistent with the similar TCF magnitude between upper and deep traps. TCF measured at $500 \mathrm{~m}$ depth during Mooring 2 is significantly lower with respect to Mooring 1 , and we suspect that calcite dissolution may have partly occurred in the samples. Thus this part of the time series might not be fully reliable.

We may thus conclude that at the Urania site, fluxes are extremely high in May-June 2000, i.e., at the beginning of summer, and are generally larger in the autumn and spring seasons.

TPF measured at $2800 \mathrm{~m}$ depth at the Bannock site is depicted in Fig. 8 with a light-gray line; Current Vertical Velocity (CVV), averaged between $100 \mathrm{~m}$ and $600 \mathrm{~m}$ depth and on an area of $85 \mathrm{~km}$ side (area $\mathrm{E}$ ), is superimposed on the same plot with a dark-gray line.

TPF is highest at the beginning of June 2000, when it exceeds $70 \mathrm{mg} \mathrm{m}^{-2}$ day $^{-1}$, whereas in the remaining part of the time series TPF remains below $4 \mathrm{mg} \mathrm{m}^{-2} \mathrm{day}^{-1}$, except for the period 25 February 2000-13 May 2000, when it is $10 \mathrm{mg} \mathrm{m}^{-2} \mathrm{day}^{-1}$. However, since the particles sinking throughout this period were collected in one single vial, we cannot know whether the higher TPF belongs to one single event or is due to an overall increase of flux 

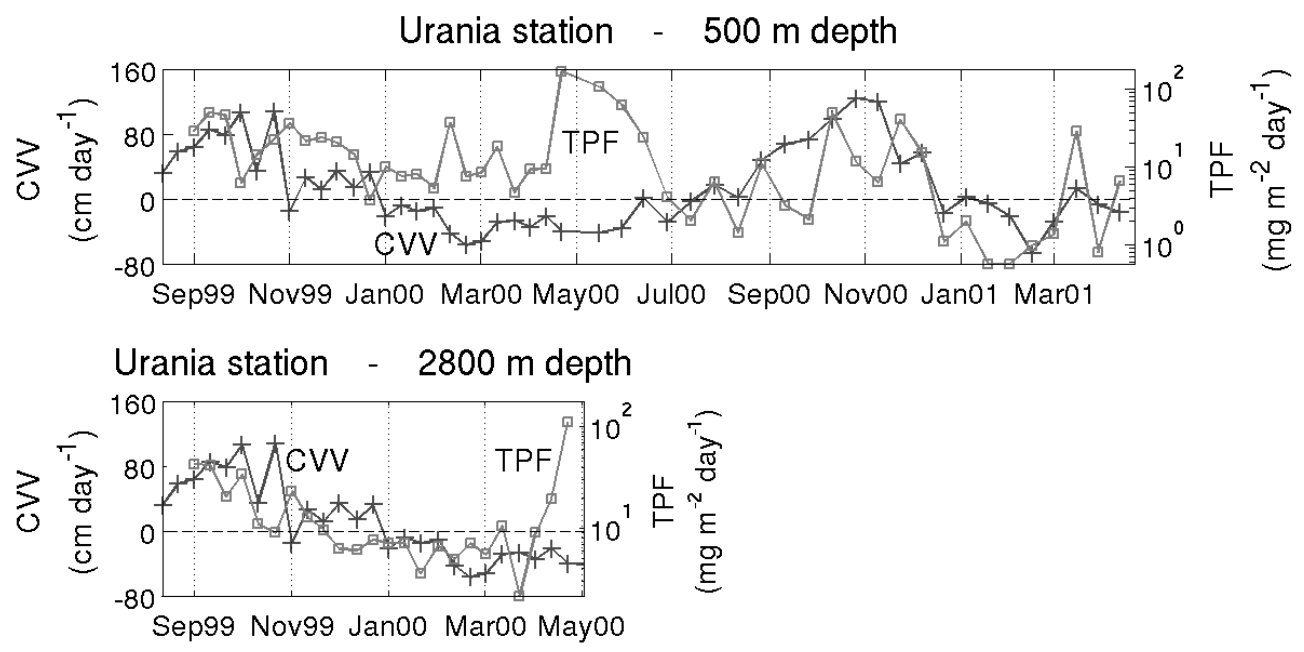

Fig. 6. Total Particle Flux (TPF) and Current Vertical Velocity (CVV) at the Urania site for Mooring 1 (15 September 1999-13 May 2000) and for Mooring 2 (30 May 2000-9 May 2001). Light-gray line: TPF ( $\mathrm{mg} \mathrm{m}^{-2} \mathrm{day}^{-1}$ ), plotted in logarithmic scale, at $500 \mathrm{~m}$ depth (top) and at $2800 \mathrm{~m}$ depth (bottom). Dark-gray line: $\mathrm{CVV}\left(\mathrm{cm} \mathrm{day}^{-1}\right)$ averaged between $100 \mathrm{~m}$ and $600 \mathrm{~m}$ depth and on a horizontal area of $85 \mathrm{~km}$ side (area $\mathrm{E}$ ). The tick marks on the $\mathrm{x}$-axis indicate the 15 th day of each month.
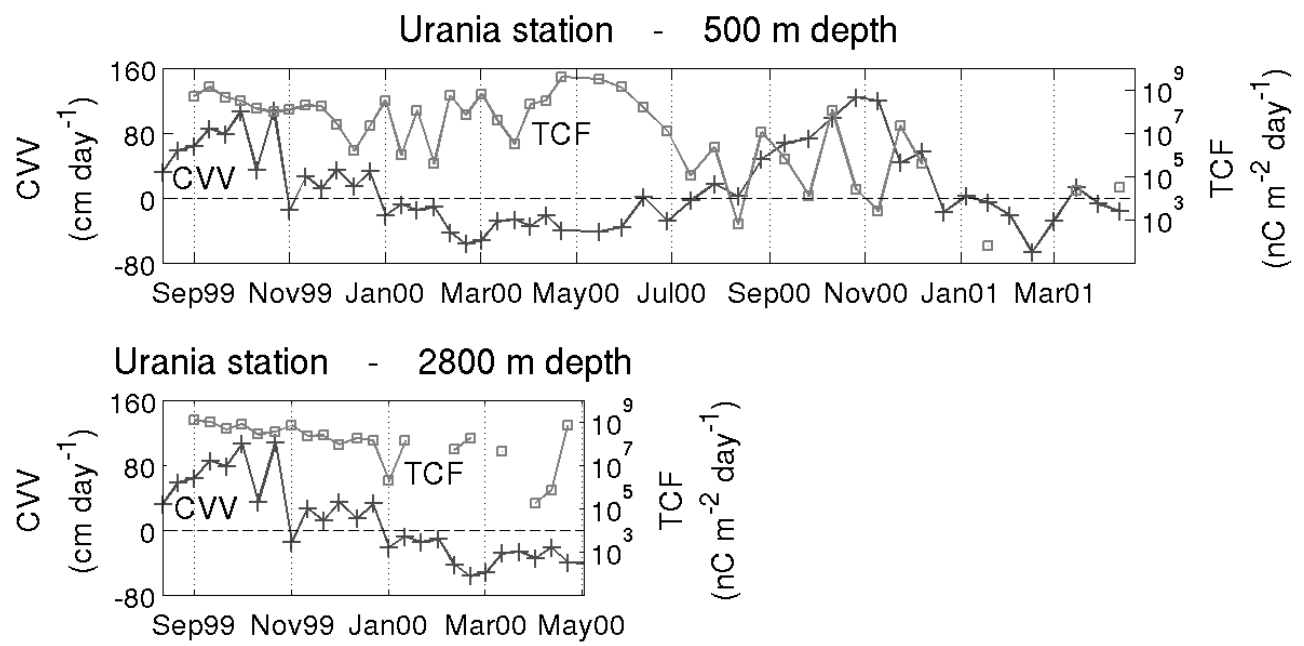

Fig. 7. Total Coccolith Flux (TCF) and Current Vertical Velocity (CVV) at the Urania site for Mooring 1 (15 September 1999 to 13 May 2000) and for Mooring 2 (30 May 2000 to 9 May 2001). Light-gray line: TCF ( $\mathrm{nC} \mathrm{m}^{-2} \mathrm{day}^{-1}$ ), plotted in logarithmic scale, at 500 depth (top) and at $2800 \mathrm{~m}$ depth (bottom). Dark-gray line: CVV (cm day ${ }^{-1}$ ) averaged between $100 \mathrm{~m}$ and $600 \mathrm{~m}$ depth and on a horizontal area of $85 \mathrm{~km}$ side (area $\mathrm{E}$ ). The tick marks on the $\mathrm{x}$-axis indicate the 15 th day of each month.

magnitude over the whole period. TPF at the Bannock site is on average $8 \mathrm{mg} \mathrm{m}^{-2} \mathrm{day}^{-1}$, with a standard deviation of $17 \mathrm{mg} \mathrm{m}^{-2}$ day $^{-1}$ (in this computation we removed the constant value of $10 \mathrm{mg} \mathrm{m}^{-2} \mathrm{day}^{-1}$ of the period 25 February-13 May 2000).

Particle fluxes measured at the Urania site are comparable with those collected in other off-shore sites of the Ionian Sea, whereas at the Bannock site they are lower. Ziveri et al. (2000) observe in fact at the Bannock site an average total particle flux at $3000 \mathrm{~m}$ depth of about $16 \mathrm{mg} \mathrm{m}^{-2}$ day $^{-1}$, while Boldrin et al. (2002) observe in the northern Ionian
Sea an average total particle flux at $2250 \mathrm{~m}$ depth of about $17 \mathrm{mg} \mathrm{m}^{-2}$ day $^{-1}$.

It is evident that some of the flux "events" appear instantaneously in the upper and deep traps. Consistently, Spearman correlation coefficients calculated between fluxes at $500 \mathrm{~m}$ and $2800 \mathrm{~m}$ depth are significant at $95 \%$ confidence level. We would like to remark that the peak of mid-May 2000 is removed from these computations, as it may represent an overestimated value of the true particle flux. Since the sediment traps at different depths are well correlated, we estimate particle settling velocities by dividing the distance between the 


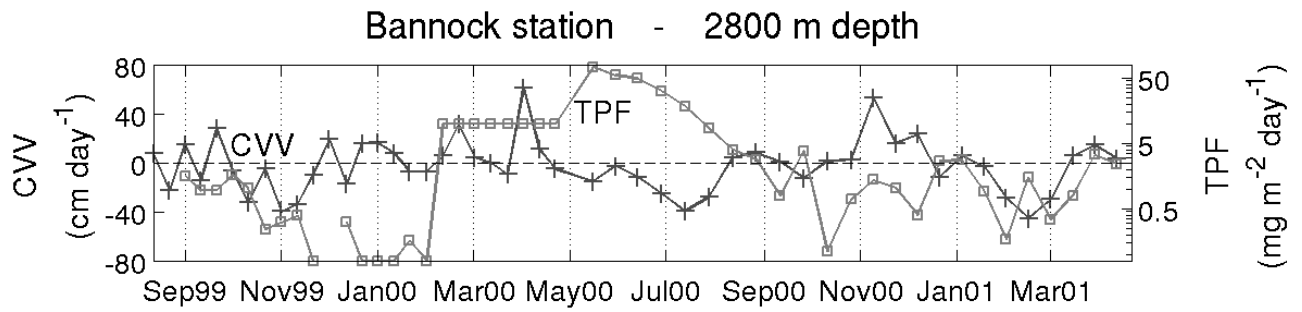

Fig. 8. Total Particle Flux (TPF) and Current Vertical Velocity (CVV) at the Bannock site for Mooring 1 (15 September 1999-13 May 2000) and Mooring 2 (30 May 2000-9 May 2001). Light-gray line: TPF $\left(\mathrm{mg} \mathrm{m}^{-2} \mathrm{day}^{-1}\right.$ ) at $2800 \mathrm{~m}$ depth plotted in logarithmic scale. Dark-gray line: CVV $\left(\mathrm{cm} \mathrm{day}^{-1}\right)$ averaged between $100 \mathrm{~m}$ and $600 \mathrm{~m}$ depth and on a horizontal area of $85 \mathrm{~km}$ side (area E). The tick marks on the $\mathrm{x}$-axis indicate the 15 th day of each month.

two traps (i.e., $2300 \mathrm{~m}$ ) by the sediment trap temporal resolution (i.e., 10 days), which yields sinking velocities higher than 200 m day $^{-1}$.

Spearman correlation coefficients between TPF measured at $500 \mathrm{~m}$ and at $2800 \mathrm{~m}$ depth are significant at $95 \%$ confidence level also with 10 days lag between the two time series. We may therefore hypothesize that a range of particle sinking velocities might be occurring in the ocean interior, with values that may vary between approximately $100 \mathrm{~m} \mathrm{day}^{-1}$ and more than $200 \mathrm{~m} \mathrm{day}^{-1}$. Fluxes of single coccolithophore species at the two investigated depths (Malinverno et al., in preparation) display a pattern that is consistent with this inference. In fact in the $500 \mathrm{~m}$ trap there is a rather distinct seasonal signal in assemblage composition, with specific abundance peaks occurring over short time intervals, whereas in the $2800 \mathrm{~m}$ trap the signal is more smoothed and occurs over longer time periods.

Particle sinking speeds between $100 \mathrm{~m} \mathrm{day}^{-1}$ and more than $200 \mathrm{~m} \mathrm{day}^{-1}$ are in general agreement with other studies conducted in open areas of the Mediterranean Sea. In the northwestern Mediterranean Sea, Lee et al. (2004) measure at $200 \mathrm{~m}$ depth a dominant particle sinking regime of $200 \mathrm{~m} \mathrm{day}^{-1}$. In the northeastern Ionian Sea, Boldrin et al. (2002), estimate particle sinking speeds higher than $140 \mathrm{~m} \mathrm{day}^{-1}$ by computing the time lag between sediment trap flux peaks measured at different depths. On the contrary Ziveri et al. (2000) estimate, in the southeastern Ionian Sea, settling rates of $17-25 \mathrm{~m} \mathrm{day}^{-1}$ for coccoliths and of more than $100 \mathrm{~m} \mathrm{day}^{-1}$ for coccospheres by calculating the time lag between the 1979-1985 satellite chlorophyll maximum, and the 1991-1994 sediment trap flux peaks at $3000 \mathrm{~m}$ depth.

3.4 Correlation between current vertical velocities and particle fluxes

CVVs at the Urania site (Figs. 6 and 7) exhibit positive values exceeding $80 \mathrm{~cm} \mathrm{day}^{-1}$ in September-November 1999 and in November-December 2000, whereas negative values lower than $-30 \mathrm{~cm} \mathrm{day}^{-1}$ occur in March 2000, in May-June 2000 and in February 2001. Thus we observe an increase in up- ward motion in autumn and an increase in downward motion in late winter and summer. CVVs at the Bannock site (Fig. 8) remain close to zero $\left(< \pm 30 \mathrm{~cm} \mathrm{day}^{-1}\right)$ during most of the time series, except for two sporadic peaks in April 2000 and November $2000\left(>50 \mathrm{~cm} \mathrm{day}^{-1}\right)$ and negative values below $-30 \mathrm{~cm} \mathrm{day}^{-1}$ in November 1999, August 2000 and March 2001.

Periods of upward vertical velocities are normally associated with higher particle fluxes. This behavior is observed at the Urania site in September-November 1999 and in November-December 2000. Periods of downward vertical velocities appear instead to coincide with periods of low particle fluxes, as seen at the Urania site in late winter 2000 (only at $2800 \mathrm{~m}$ depth) and 2001, and at the Bannock site in November 1999 and late winter 2001. When ocean vertical velocities remain close to zero, as seen in most of the Bannock time series, there appears to be no evident correlation with particle fluxes.

An exception to this pattern occurs in May-June 2000, when the high particle flux occurring at both the Urania and Bannock sites is not associated with a large increase of upward CVVs. We decided to remove the May-June 2000 flux event from the remaining computations: we believe in fact that mechanisms other than ocean vertical velocities are determining the observed strong particle fluxes, as it will be discussed further on.

In Fig. 9 we show, for the Urania site, Spearman correlation coefficients between CVV and particle fluxes, for the three cases "0 lag", "1 lag" and "2 lags". Correlation coefficients are plotted as a function of the horizontal integration area of CVV, where area $\mathrm{A}$ is the largest (145 km side) and area $\mathrm{F}$ is the smallest $(70 \mathrm{~km}$ side $)$. The correlation value marking the $90 \%$ confidence level is depicted with a dashed line.

During Mooring 1, TPF at $500 \mathrm{~m}$ depth is significantly correlated with CVV at $90 \%$ confidence level in the " 1 lag" and "2 lags" cases, whereas at $2800 \mathrm{~m}$ depth significant correlation coefficients occur for all time lags ("0 lag", "1 lag", "2 lags"). TCF at $500 \mathrm{~m}$ depth is not significantly correlated 

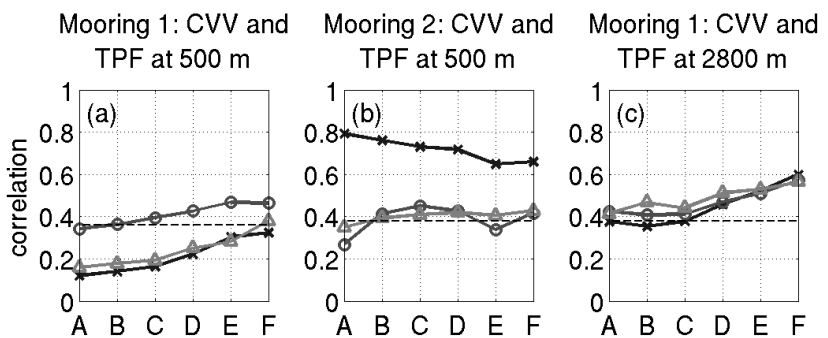
TPF at $2800 \mathrm{~m}$
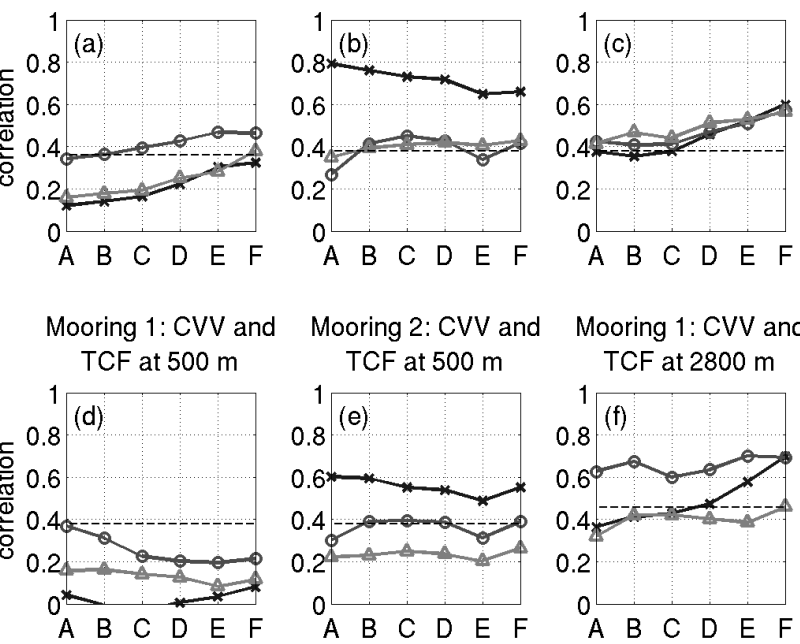
TCF at $500 \mathrm{~m}$

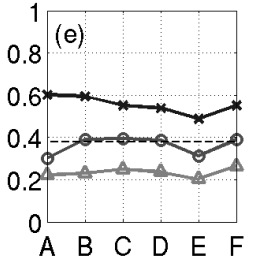

Mooring 1: CVV and TCF at $2800 \mathrm{~m}$
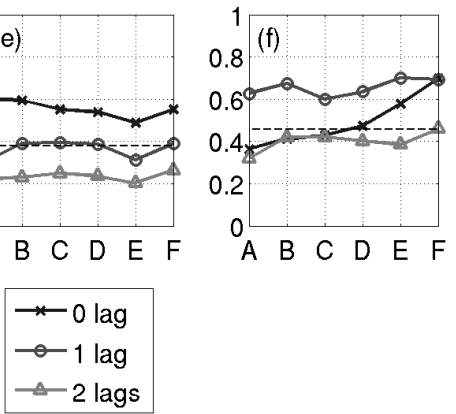

At the Bannock station correlation coefficients for Mooring 1 cannot be computed because of the discontinuity of the time series and for Mooring 2 they are not statistically significant.

\section{Discussion}

4.1 Correlation between particle fluxes and upward vertical velocities

The positive correlation between upward vertical velocities and particle fluxes might seem at first sight surprising, as we might expect downward vertical velocities to enhance particle fluxes by increasing vertical settling rates. However particle sinking rates estimated from sediment traps are two orders of magnitude higher with respect to ocean vertical velocities calculated from the model output, which are around $1 \mathrm{mday}^{-1}$. We thus exclude, in the region analyzed in this study, a direct effect of ocean vertical velocities on particle sinking rates and thus particle fluxes.

In correspondence of submesoscale features, arising as a

Fig. 9. Spearman correlation coefficients between Current Vertical Velocity (CVV), vertically averaged between $100 \mathrm{~m}$ and $600 \mathrm{~m}$ depth, and (a) Total Particle Flux (TPF) at $500 \mathrm{~m}$ depth for Mooring 1 (15 September 1999-13 May 2000), (b) TPF at $500 \mathrm{~m}$ depth for Mooring 2 (30 May 2000-9 May 2001), (c)TPF at $2800 \mathrm{~m}$ depth for Mooring 1, (d) Total Coccolith Flux (TCF) at $500 \mathrm{~m}$ depth for Mooring 1, (e) TCF at $500 \mathrm{~m}$ depth for Mooring 2, (f) TCF at $2800 \mathrm{~m}$ depth for Mooring 1 . CVVs are horizontally averaged over 6 areas of increasingly higher dimension, where area $\mathrm{A}$ is the largest ( $145 \mathrm{~km}$ side) and area $\mathrm{F}$ is the smallest (70 km side). Correlation coefficients are calculated between coincidental time series ("0 lag") and between time series shifted of one ("1 lag") and two ("2 lags") sediment trap rotation intervals. The correlation value marking the $90 \%$ confidence level is depicted with a dashed line.

with CVV, whereas at $2800 \mathrm{~m}$ depth it exhibits significant correlations at $90 \%$ confidence level for the " 0 lag" and " 1 lag" cases. During Mooring 2, TPF at $500 \mathrm{~m}$ depth is significantly correlated with CVV at $90 \%$ confidence level for all time lags ("0 lag", "1 lag", "2 lags"), whereas for TCF at $500 \mathrm{~m}$ depth significant correlations occur only in the " 0 lag" and "1 lag" cases.

Thus in general we observe that correlation coefficients are higher for TPF with respect to TCF, and at $2800 \mathrm{~m}$ depth with respect to $500 \mathrm{~m}$ depth; moreover correlations appear to be in many cases higher when the horizontal average of $\mathrm{CVV}$ is performed on the smallest area $\mathrm{F}$ around the Urania station coordinates. Even though characterized by some heterogeneity, correlation coefficients appear to be overall robust with respect to the horizontal integration area of ocean vertical velocities. gions of strong shears, large vertical velocities higher than $10 \mathrm{~m} \mathrm{day}^{-1}$ may occur (Lévy et al., 2001; Mahadevan, 2006). The OGCM used in the present study, characterized by approximately $6 \mathrm{~km}$ horizontal resolution, is too coarse to resolve submesoscale features and associated high vertical velocities. However enhanced density gradients and velocity shears leading to the formation of submesoscale structures are not a predominant feature of our study area and we do not expect this to be a substantial mechanism in this region.

The high sinking rates estimated in this work might be attained by means of biological aggregation of particles inside fecal pellets produced by macro-zooplankton. Mazzocchi et al. (2003) detect in the Ionian Sea an eastward increase of pelagic tunicates' abundance in the year 1999. Pelagic tunicates feed on phytoplankton by filtering large volumes of water and are adapted to dilute environments, where they exhibit a rapid population growth if environmental conditions are favorable (Alldredge and Madin, 1982). Their fecal pellets sink at a speed ranging between 242 and $2700 \mathrm{~m}$ day $^{-1}$ for salps (Bruland and Silver, 1981; Yoon et al., 1996; Yoon et al., 2001) and between 25 and $504 \mathrm{~m} \mathrm{day}^{-1}$ for appendicularians and doliolids (Turner, 2002 and references therein).

We hypothesize that the following sedimentation mechanism might be occurring in the open areas of the Eastern Mediterranean Sea. An upward vertical velocity at the base of the euphotic layer would produce a vertical isopycnal displacement and a nutrient uplift in the sunlight layer. Phytoplanktonic organisms would take advantage of higher nutrient levels giving rise to enhanced primary production, which would eventually stimulate grazing. The biogenic material would then sink through the water column inside rapidly 
sinking fecal pellets or other large particles and would be collected by sediment traps.

According to our results, the described mechanism of enhanced particle fluxes triggered by upward CVVs appears to occur within a temporal range of a few weeks. The fact that correlations between CVV and TPF at $500 \mathrm{~m}$ depth are highest with " 1 lag" for Mooring 1 and with " 0 lag" for Mooring 2 is not necessarily an inconsistent result, as the temporal resolution is of 10 days for Mooring 1 and of 15 days for Mooring 2. Significant correlations between CVV and both coincidental and lagged particle flux time series might be indicating that various time scales are involved in the sedimentation of particle pulses from the ocean surface. We may speculate that this is due to the existence of a spectrum of particle sinking rates in the ocean interior. However, due to the shortness of the time series, the robustness of temporally lagged correlation results might be questioned and caution must be used in drawing conclusions.

The observation that correlations generally increase when CVV is horizontally averaged on the smallest area $\mathrm{F}$ around the station coordinates gives strength to our hypothesis, as it would highlight the local effect of CVVs on the observed particle fluxes. Higher correlations occurring for the $2800 \mathrm{~m}$ depth trap - with respect to the $500 \mathrm{~m}$ depth trap - might indicate that sediment trap measurements at $500 \mathrm{~m}$ depth are more affected by upper ocean dynamics (e.g. vertical migrating organisms, higher abundance of zooplanktonic "swimmers").

Both TCF and TPF are significantly correlated with CVVs and we hypothesize that this might be due to a high percentage of biogenic matter to the total particle flux. Zuñiga et al. (2008) observe, in the open Algero-Balearic basin, that biogenic flux contributes to about $50 \%$ of total particle flux, with calcium carbonate being a major constituent $(\sim 25 \%$ of total particle flux, with a maximum of $60 \%$ during winter). Our results show however that TPF, rather than TCF, is giving the highest correlations with CVV and we propose two reasons for this behavior. First of all TPF contains, in addition to coccoliths, other sinking matter of biogenic origin (Zuñiga et al., 2008): TPF may therefore be, in areas of low lithogenic inputs, a better proxy of upper ocean productivity than TCF itself. Secondly, the measure of TPF may be intrinsically more precise than the measure of TCF: the latter is only an estimate of the true coccolith flux and moreover, because of the various steps of the sampling and measuring procedures, there is a non-null risk for coccolith plates to undergo partial dissolution.

At the Bannock site, where CVVs are close to zero during most of the studied period, CVVs do not appear to affect particle flux variability in any evident way, and the proposed mechanism of enhanced particle fluxes triggered by upward CVVs is not valid. In the next sections we will analyze additional data sets that may help to improve our understanding of the sedimentary processes at the Urania and Bannock sites during the studied period.

\subsection{Relationship with SeaWiFS chlorophyll-a data}

To support our discussion on enhanced primary production triggered by upward CVVs, we analyze SeaWiFS chlorophyll-a monthly means available from the JRC Ocean Color Portal (http://oceancolour.jrc.ec.europa.eu) for the years 1999-2004. The data, which have a horizontal resolution of approximately $2 \mathrm{~km}$ in our study area, are used to compute average chlorophyll concentrations at the Urania and Bannock sites. We analyze total chlorophyll values (hereafter referred to as CHL-T) and chlorophyll anomalies with respect to the long-term seasonal mean (hereafter referred to as CHL-A). In Figs. 10 and 11 we depict, at the Urania and Bannock sites respectively, CHL-T and CHLA together with CVV and TPF. CVV, CHL-T and CHL-A are horizontally averaged over an area of $70 \mathrm{~km}$ side (area F) around the station coordinates.

At both the Urania and Bannock sites, CHL-T exhibits a well developed seasonal cycle with maximum values in the late winter months (up to $0.1 \mathrm{mg} \mathrm{Chl} \mathrm{m}^{-3}$ ) and minimum values in the summer months (below $0.04 \mathrm{mg} \mathrm{Chl} \mathrm{m}^{-3}$ ). The Urania and Bannock chlorophyll concentration values are characterized by equivalent mean values (i.e. approximately $0.05 \mathrm{mg} \mathrm{m}^{-3}$ ) and seasonality (i.e. seasonal maximum in February-March). This chlorophyll concentration pattern is typical of a subtropical oligotrophic setting where light is never limiting and nutrients are conveyed seasonally in the eutrophic layer by means of winter mixing. CHL-A values, i.e. the interannual chlorophyll fluctuations around the seasonal mean, are confined between $\pm 0.03 \mathrm{mg} \mathrm{Chl} \mathrm{m}^{-3}$ at both the Urania and Bannock sites.

CVV does not exhibit any evident correspondence with CHL-T, whereas it appears to be more synchronously correlated with CHL-A values, as it may be seen at Urania site in autumn 1999 and 2000 (positive CHL-A, upward CVVs) and in winter 2000 and 2001 (negative CHL-As, downward CVVs) and at the Bannock site in March 2000 (positive CHL-As, upward CVVs) and in late winter 2001 (negative CHL-As, downward CVVs). We may attribute the lack of correlation between CVV and CHL-T to the predominant role played by vertical mixing - rather than water column upward displacement - in causing the winter increase in chlorophyll concentration. Vertical isopycnal displacements at the base of the euphotic layer (McGillicuddy et al., 2001) appear instead to affect the interannual variability of chlorophyll concentration values, even though in this area also other processes, such as Saharan dust fertilization, are certainly relevant in determining chlorophyll interannual fluctuations.

When comparing CHL-T and TPF fields, we notice that a direct correspondence between the two fields is not readily observed. The Urania and Bannock sites, even though characterized by equivalent upper ocean chlorophyll patterns, exhibit however very dissimilar deep export regimes (TPFs at the Bannock site are generally an order of magnitude lower than at the Urania site). In addition, the seasonality of algal 


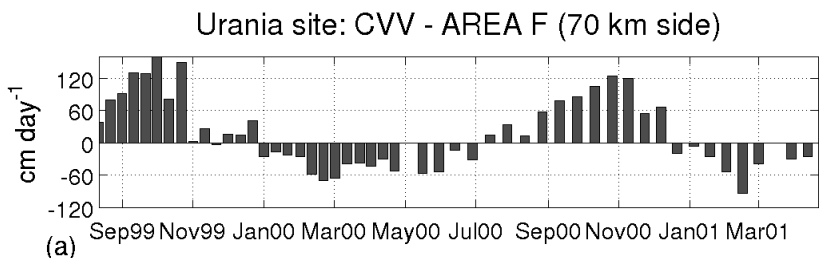

Urania site: CHL-T - AREA F (70 km side)

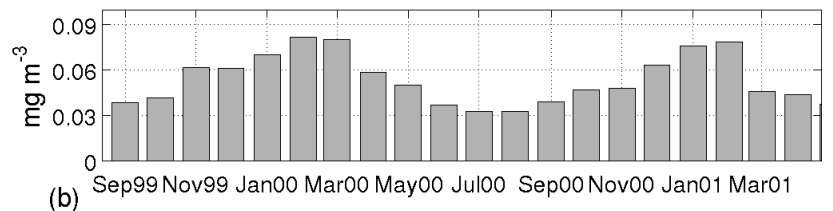

Urania site: CHL-A - AREA F (70 km side)

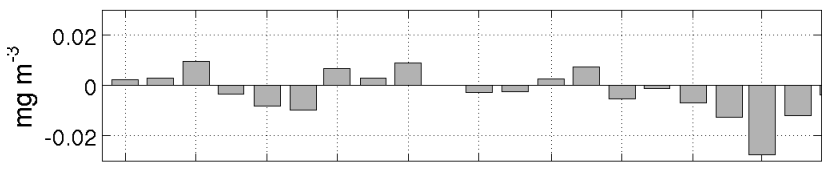

(c)

Sep99 Nov99 Jan00 Mar0o May00 Jul00 Sep00 Nov00 Jan01 Mar01

Urania site: TPF at $500 \mathrm{~m}$ depth

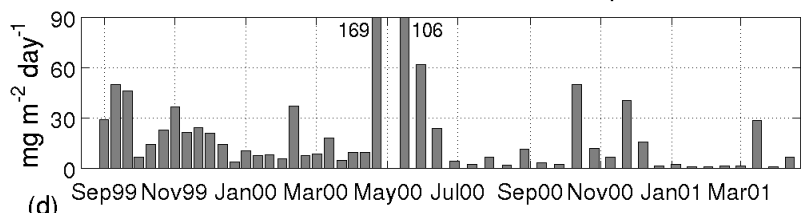

(d) Sep99 Nov99 Jan00 Mar00 May00 Jul00 Sep00 Nov00 Jan01 Mar01

Fig. 10. Urania site: (a) simulated Current Vertical Velocities $(\mathrm{CVV})$ in $\mathrm{cm} \mathrm{day}^{-1}$ vertically averaged between $100 \mathrm{~m}$ and $600 \mathrm{~m}$ depth, (b) SeaWiFS chlorophyll-a concentration (CHL$\mathrm{T}$ ) in $\mathrm{mg} \mathrm{m}^{-3}$, (c) SeaWiFS chlorophyll-a concentration anomalies (CHL-A) in $\mathrm{mg} \mathrm{m}^{-3}$, (d) Total Particle Flux (TPF) in $\mathrm{mg} \mathrm{m}^{-2}$ day $^{-1}$ at $500 \mathrm{~m}$ depth. CVV, CHL-T and CHL-A are horizontally averaged over an area of $70 \mathrm{~km}$ side (area F) around the station coordinates. The tick marks on the $\mathrm{x}$-axis indicate the 15 th day of each month.

biomass magnitude does not appear to directly determine particle flux variability. On the contrary, TPFs appear to respond with a similar magnitude to the winter chlorophyll concentration maximum (peaks in late winter 2000 and 2001 at the Urania site) and to its interannual anomalies: higher than average TPFs often concur with positive CHL-A values (autumn 1999 and 2000 and late spring 2000 at the Urania site; spring 2000 at the Bannock site), whereas lower than average TPFs are often associated with negative CHL-A values (late summer 2000 and winter 2000 and 2001 at the Urania site; winter 2001 at the Bannock site).

These results suggest a non-linear relationship between upper ocean algal biomass and deep sedimentary fluxes, with an amplification of the summer-autumn response of particle fluxes to upper chlorophyll amount with respect to winter and early spring. The weak coupling between primary producers and deep particle fluxes supports the hypothesis that particle export depends, in addition to primary production,

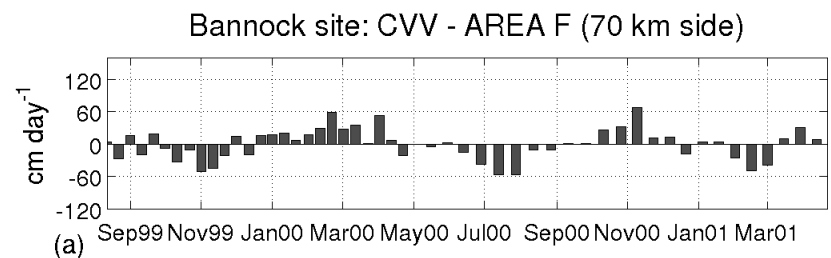

Bannock site: CHL-T - AREA F (70 km side)

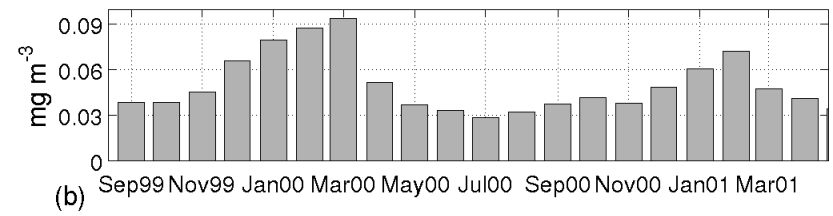

Bannock site: CHL-A - AREA F (70 km side)

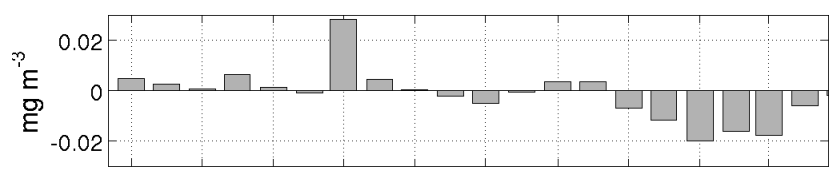

(c) Sep99 Nov99 Jan00 Mar00 May00 Jul00 Sep00 Nov00 Jan01 Mar01

Bannock site: TPF at $2800 \mathrm{~m}$ depth

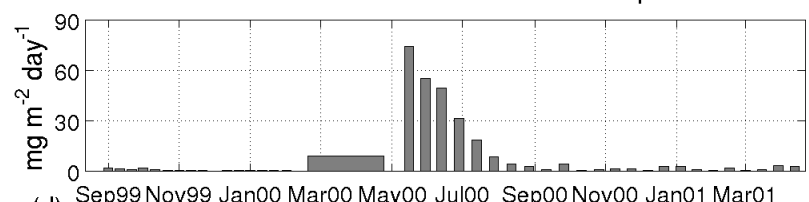

(d) Sep99 Nov99 Jan00 Mar00 May00 Jul00 Sep00 Nov00 Jan01 Mar0

Fig. 11. Bannock site: (a) simulated Current Vertical Velocities (CVV) in $\mathrm{cm} \mathrm{day}^{-1}$ vertically averaged between $100 \mathrm{~m}$ and $600 \mathrm{~m}$ depth, (b) SeaWiFS chlorophyll-a concentration (CHL-T) in $\mathrm{mg} \mathrm{m}^{-3}$, (c) SeaWiFS chlorophyll-a concentration anomalies (CHL-A) in $\mathrm{mg} \mathrm{m}^{-3}$, (d) Total Particle Flux (TPF) in $\mathrm{mg} \mathrm{m}^{-2}$ day $^{-1}$ at $2800 \mathrm{~m}$ depth. CVV, CHL-T and CHL-A are horizontally averaged over an area of $70 \mathrm{~km}$ side (area F) around the station coordinates. The tick marks on the $\mathrm{x}$-axis indicate the 15 th day of each month.

also on the biological pump efficiency. Other studies have shown that in oligotrophic areas primary production and particle fluxes are often decoupled (Buesseler, 1998; Conte et al., 2001; Lutz et al., 2002) and that the sinking fraction of primary production varies seasonally possibly in response to flux biodegradability (Lutz et al., 2007). These results argue for a relevant role of the food web structure, sedimentation pathways and particle properties in affecting deep particle fluxes. From our data it is possible to speculate on three possible factors affecting the biological pump: 1) grazer community composition and activity; 2) phytoplankton coagulation processes; 3) particle properties connected to Saharan dust events.

1. The pulsed-like behavior of particle flux maxima in autumn 1999 and 2000 at the Urania site could be linked to the occurrence of macrozooplankton swarms (Conte et al., 2003) which would efficiently feed on the positive 

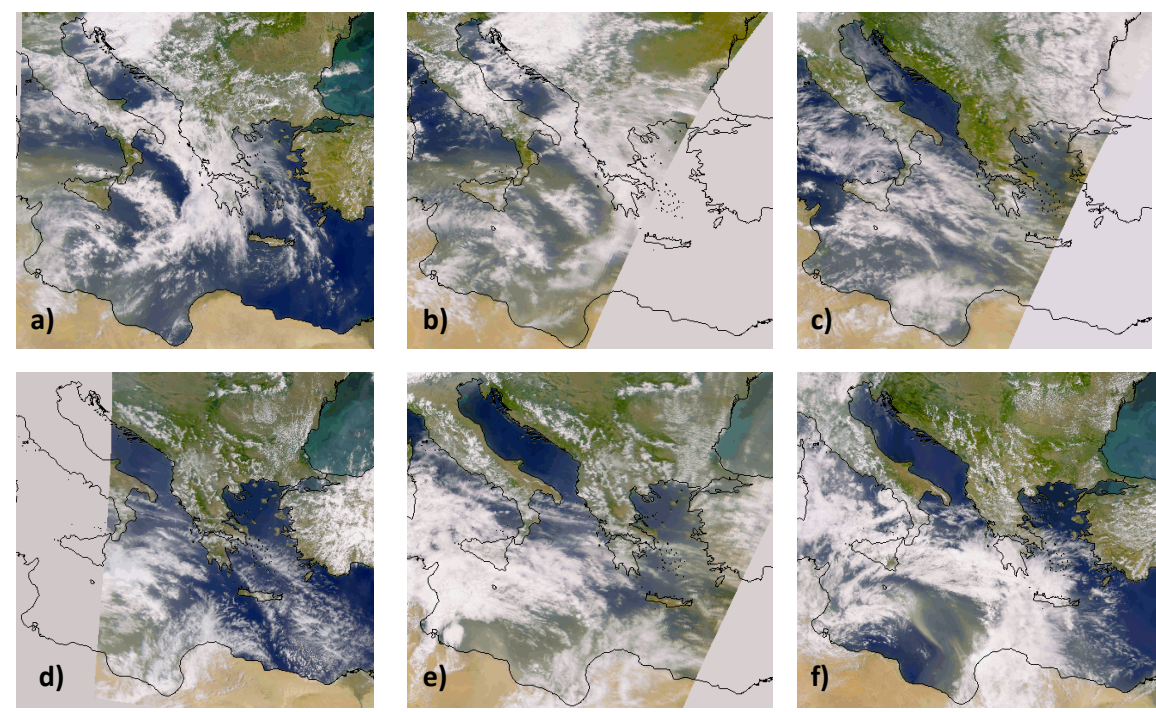

Fig. 12. Quasi True Color satellite images: (a) 22 May 2000 at 10:36 a.m., (b) 22 May 2000 at 12:14 a.m., (c) 24 May 2000 at 12:02 a.m., (d) 26 May 2000 at 10:15 a.m., (e) 26 May 2000 at 11:51 a.m., (f) 27 May 2000 at 10:57 a.m.

chlorophyll anomalies generated by upward CVVs. Observations in coastal areas of the Mediterranean Sea show that warm-dwelling species of pelagic tunicates, such as $O$. dioica, D. nationalis and $T$. democratica, exhibit their seasonal maximum in spring-summer and autumn (Avancini et al., 2006). We could then speculate that gelatinous zooplankton organisms in this area would be mostly abundant during the summer and autumn months whereas they would be lower in winter. If this is the case, the summer and autumn particle flux pulses at the Urania site might be related to higher macrozooplankton abundance. The discrepancy between the Urania and Bannock particle fluxes could then be related to differences in macrozooplankton populations at the two sites.

2. The exudation by phytoplankton organisms - including coccolithophores - of transparent exopolymer particles (TEP) may be playing a relevant role in promoting phytoplankton aggregation and export at depth (Engel, 2004). Beauvais et al. (2003) observe, in an offshore site of the western Mediterranean Sea, an increase in TEP volume after the spring bloom and throughout the summer months, and they relate this feature to increases in carbon excretion by phytoplankton and to thermally stratified conditions. Thus it is possible that during summer there may be more favorable conditions for TEP-enhanced phytoplankton aggregation followed by higher particle fluxes.

3. The higher frequency of Saharan dust events in summer might be responsible for the high particle flux event in May-June 2000, as it will be discussed in Sect. 4.3.

\subsection{Dust-enhanced particle fluxes in May-June 2000}

Between mid-May and the beginning of June 2000, a strong particle flux peak occurs at both the Urania and Bannock sites (Figs. 6, 7 and 8). Since we cannot fully trust the particle flux peak occurring in mid-May (because of the incorrect sediment trap opening) we concentrate on the particle flux peak occurring at the beginning of June 2000. We suggest that this event may be due to a Saharan dust pulse, which would enhance lithogenic and possibly biogenic flux.

Saharan dust transport over the Mediterranean occurs frequently in spring and summer in the form of non-continuous "pulses" (Kubilay et al., 2000). Dust particles may represent an important source of nutrients in the euphotic layer (Markaki et al., 2003; Herut et al., 2005), and may act as ballast on organic matter settling within the ocean interior (Klaas and Archer, 2002). Zuñiga et al. (2008) observe in the open Algero-Balearic Basin an increase of particle fluxes (and of the lithogenic fraction therein) associated with summer and autumn Saharan dust pulses.

A time series of SeaWiFS Quasi True Color (QTC) satellite images for the period 22 May-13 July 2000 is available. QTC images are generated by combining the three SeaWiFS bands that most closely represent red, green and blue in the visible spectrum. This procedure creates an image which is very close to what the human eye would perceive from space (Sciarra et al., 2006). The effectiveness of QTC images in detecting intense dust events is documented in Volpe et al. (2009). The analysis of QTC images for our study area reveals a Saharan dust event occurring in the period 22-27 May 2000 (Fig. 12) which we may reasonably consider responsible for the high particle flux peak detected in the Urania and Bannock sediment traps at the beginning of June 2000. 


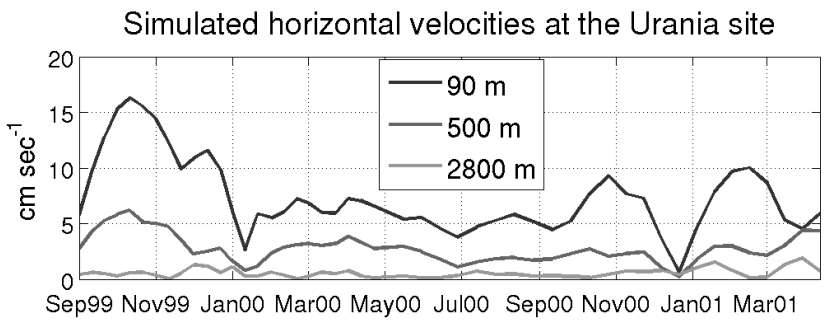

Simulated horizontal velocities at the Bannock site

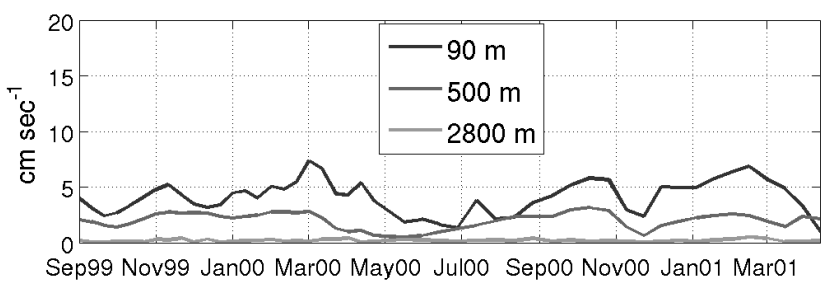

Fig. 13. Simulated current horizontal velocities $\left(\mathrm{cm} \mathrm{s}^{-1}\right)$ at $90 \mathrm{~m}$, $500 \mathrm{~m}$ and $2800 \mathrm{~m}$ depth at the Urania (top) and Bannock (bottom) sites, temporally averaged over the sediment trap rotation intervals. The tick marks on the $\mathrm{x}$-axis indicate the 15 th day of each month.

\subsection{Impact of horizontal advection}

In Fig. 13 we show, for the Urania and Bannock sites, simulated horizontal currents at $90 \mathrm{~m}, 500 \mathrm{~m}$ and $2800 \mathrm{~m}$ depth, temporally averaged over the sediment trap rotation intervals. Horizontal currents at the Urania site have a mean of 7.5-2.8-0.6 $\mathrm{cm} \mathrm{s}^{-1}$ at 90-500-2800 $\mathrm{m}$ depth respectively, whereas at the Bannock site they have a mean of 4.1-2.0$0.2 \mathrm{~cm} \mathrm{~s}^{-1}$ at $90-500-2800 \mathrm{~m}$ depth respectively. At $90 \mathrm{~m}$ depth, horizontal currents at the Urania site are higher with respect to the Bannock site, and a rather pronounced seasonality is evident, with strongest currents $\left(>15 \mathrm{~cm} \mathrm{~s}^{-1}\right)$ occurring in autumn 1999. On the other hand, at $500 \mathrm{~m}$ and $2800 \mathrm{~m}$ depth mean currents are lower in amplitude $\left(<5 \mathrm{~cm} \mathrm{~s}^{-1}\right)$ and almost stationary with greater variability again at the Urania site.

Because horizontal velocities in our study area are generally well below $5 \mathrm{~cm} \mathrm{~s}^{-1}$ at both $500 \mathrm{~m}$ and $2800 \mathrm{~m}$ depth, we do not expect a significant impact of hydrodynamics on sediment trap collecting efficiency (Buesseler et al., 2007). Lateral advection in the upper ocean may however modify the source region of particles collected by deep sediment traps (Siegel et al., 2008). This process might be occurring in particular at the Urania site, where horizontal velocities up to $10-15 \mathrm{~cm} \mathrm{~s}^{-1}$ (i.e. approximately $10 \mathrm{~km} \mathrm{day}^{-1}$ ) would cause a lateral transport of upwelled nutrients and primary producers of about 100-200 km during a 10-15 day period. We expect instead that the Bannock site, where simulated currents at $90 \mathrm{~m}$ depth are normally below $5 \mathrm{~cm} \mathrm{~s}^{-1}$, will be more representative of local conditions.

To evaluate the qualitative aspects of lateral advection of primary producers at the Urania site, we compare chloro-
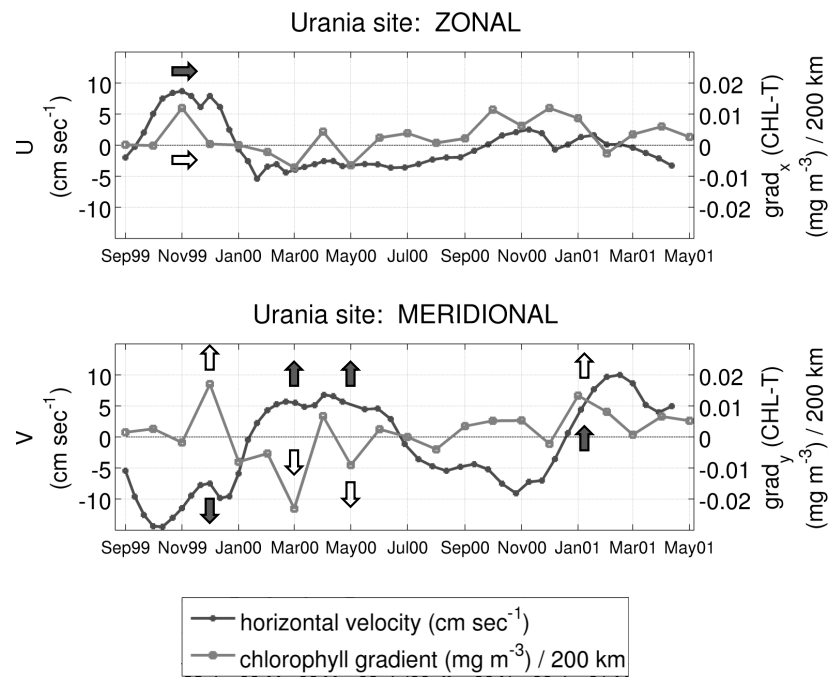

Fig. 14. Urania site: simulated current horizontal velocities at $90 \mathrm{~m}$ depth $\left(\mathrm{cm} \mathrm{s}^{-1}\right)$ and SeaWiFS chlorophyll-a concentration (CHLT) gradients computed over a $200 \mathrm{~km}$ side area $\left(\mathrm{mg} \mathrm{m}^{-3} / 200 \mathrm{~km}\right)$. Top: zonal velocities (U) and zonal CHL-T gradients; bottom: meridional velocities (V) and meridional CHL-T gradients. With arrows we indicate the direction of lateral advection (grey arrows) and of positive chlorophyll gradients (white arrows) during periods when these simultaneously exceed $5 \mathrm{~cm} \mathrm{~s}^{-1}$ and $0.01 \mathrm{mg} \mathrm{m}^{-3} / 200 \mathrm{~km}$ respectively.

phyll concentration gradients characterizing the study area with horizontal current velocities at $90 \mathrm{~m}$ depth, i.e. approximately at the base of the euphotic layer. We use SeaWiFS chlorophyll-a monthly means available for the years 19992004 to compute zonal and meridional chlorophyll concentration gradients on a $200 \mathrm{~km}$ side area around the Urania site. In Fig. 14 these values are plotted together with zonal and meridional current velocities at $90 \mathrm{~m}$ depth. We indicate with grey arrows the direction of zonal (i.e., west-east) and meridional (i.e., south-north) velocities and with white arrows the direction of positive chlorophyll gradients, during periods when these simultaneously exceed $5 \mathrm{~cm} \mathrm{~s}^{-1}$ (i.e. approximately $4 \mathrm{~km} \mathrm{day}^{-1}$ ) and $0.01 \mathrm{mg} \mathrm{m}^{-3} / 200 \mathrm{~km}$ respectively. The choice of these threshold values is not based on quantitative arguments: our aim here is only to make our qualitative description clearer.

We can write a simplified equation accounting for the local rate of change of chlorophyll concentration due to horizontal advection as:

$\frac{\partial C h l}{\partial t} \approx-u \frac{\partial C h l}{\partial x}-v \frac{\partial C h l}{\partial y}$,

where $C h l$ is chlorophyll concentration and $u$ and $v$ the zonal and meridional ocean velocities respectively. According to Eq. (5) when horizontal velocity and chlorophyll gradients have opposite sign, we expect an enhancement of local chlorophyll values by horizontal advection (as it could be 
occurring in December 1999, March and May 2000); when horizontal velocity and chlorophyll gradients have the same direction, we expect lateral advection to cause instead a reduction of local chlorophyll values (as it could be occurring in November 1999 and in January-February 2001). We may then speculate that part of the particle flux increase occurring in December 1999 and in March-May 2000 at the Urania site may be due to lateral advection from more productive regions near the site. On the other hand in January-February 2001 particle fluxes may be particularly low because of lateral chlorophyll divergence away from the station.

However we also recall that correlation coefficients between CVV and particle fluxes are overall robust with respect to the spatial integration area of CVV (Fig. 9): it could then be argued that, for our studied period and area, horizontal advection is not changing the spatial distribution of particles to such an extent to provoke a substantial effect on CVV-TPF correlations.

\section{Conclusions}

The mechanisms of sedimentary particle fluxes in the deep Urania and Bannock sites are studied by means of sediment trap records and model simulated vertical velocities.

The current vertical velocities in the Ionian Sea have a large mesoscale signal that is superimposed to a seasonally varying Ekman vertical velocity field at low amplitude. It is found that current vertical velocities at the Urania site are positive (upward motion) in autumn, when pulses of total particle fluxes are found in the water column at $500 \mathrm{~m}$ and $2800 \mathrm{~m}$ depth.

From sediment trap data the sinking velocities of TPF and TCF are estimated to be $100-200 \mathrm{~m} \mathrm{day}^{-1}$ while current vertical velocities are estimated to be around $1 \mathrm{mday}^{-1}$. This observation brought us to envisage a tight coupling between surface and deep layers through particle aggregation mechanisms. We suggested that fast sinking rates of organic material in the deep ocean are connected to both lithogenic and biological aggregation mechanisms that transfer particles rapidly in the deep water column.

In synthesis two emerging fast sinking mechanisms have been captured:

1. Pulses of primary production, triggered by upward current vertical velocities, followed by grazing and macrozooplankton-related biogenic flux that rapidly conveys the material in the deep ocean.

2. Large Saharan dust events that fertilize the upper ocean and possibly contribute to aggregation of organic material, thus producing high sedimentation fluxes.
If these mechanisms are at work in other open ocean areas, it is possible to argue that the carbon export to the deep ocean is larger in the cyclonic gyres of the ocean general circulation and during the months of maximum upward vertical velocities. The fast sinking rates estimated in this study could be moreover an evidence of the efficiency of the biological pump in sequestering organic carbon from the surface layers of the open areas of the Mediterranean Sea. Further work is however needed to unravel the relevant physical and biological features of the marine environment capable of affecting deep particle fluxes.

Acknowledgements. This work has been supported by the Italian Project VECTOR (VulnErability of the Italian coastal area and marine Ecosystems to Climatic changes and Their rOle in the Mediterranean caRbon cycles) funded by the Italian Ministry of Research and University (http://vector-conisma.geo.unimib.it/). Sediment trap samples were available for the study of biogenic particles within an Italian-Dutch cooperation agreement. Mooring equipment was made available by NWO/ALW, through the Dutch Marine Research Facilities at NIOZ; ship-time was funded alternatively by NWO and the Italian CoNISMa (National Interuniversity Consortium for Marine Sciences). The study of biogenic particles was performed within the European Project BIODEEP (BIOtechnologies from the DEEP, EVK3-2000-00042). The SeaWiFS derived products have been processed by CNR-ISAC, and obtained from the E.C. Joint Research Centre, Institute for Environment and Sustainability, through its MERSEA portal (FP6-EC project-SIP3CT-2003-502885). The Ocean Biology Processing Group of NASA is also acknowledged for the distribution of the SeaWiFS raw data.

Edited by: A. Borges

\section{References}

Agostini, V. N. and Bakun, A.: "Ocean triads" in the Mediterranean Sea: physical mechanisms potentially structuring reproductive habitat suitability (with example application to European anchovy, Engraulis encrasicolus), Fish Oceanogr., 11(3), 129_ 142, 2002.

Alldredge, A. L. and Madin, L. P.: Pelagic tunicates - unique herbivores in marine plankton, Bioscience, 32(8), 655-663, 1982.

Avancini M., Cicero, A. M., Di Girolamo, I., Innamorati, M., Magaletti, E., and Sertorio Zunini, T. (eds.): Guida al riconoscimento del plancton dei mari italiani, Vol. II - Zooplancton neritico. Ministero dell' Ambiente e della Tutela del Territorio e del Mare ICRAM, Roma, Italy, 192-206, 2006.

Bairbakhish, A. N., Bollmann, J., Sprengel, C., Thierstein, H. R.: Disintegration of aggregates and coccospheres in sediment trap samples, Mar Micropaleontol, 37(2), 219-223, 1999.

Beauvais, S., Pedrotti, M. L., Villa, E., Lemee, R.: Transparent exopolymer particle (TEP) dynamics in relation to trophic and hydrological conditions in the NW Mediterranean Sea, Mar. Ecol.Prog. Ser., 262, 97-109, 2003.

Berelson, W.: Particle settling rates increase with depth in the ocean, Deep-Sea Res Pt II, 49(1-3), 237-251, 2002.

Boldrin, A., Miserocchi, S., Rabitti, S., Turchetto, M. M. Balboni, V., and Socal, G.: Particulate matter in the southern Adriatic and 
Ionian Sea: characterization and downward fluxes, J. Mar. Syst., 33, 389-410, 2002.

Bricaud, A., Bosc, E., and Antoine, D.: Algal biomass and sea surface temperature in the Mediterranean Basin - Intercomparison of data from various satellite sensors, and implications for primary production estimates, Remote Sens Environ, 81(2-3), 163178, 2002.

Bruland, K. W. and Silver, M. W.: Sinking rates of fecal pellets from gelatinous zooplankton (salps, pteropods, doliolids), Mar. Biol., 63(3), 295-300, 1981.

Buesseler, K. O.: The decoupling of production and particulate export in the surface ocean, Global Biogeochem. Cy., 12(2), 297310, 1998.

Buesseler, K. O., Antia, A. N., Chen, M., Fowler, S. W., Gardner, W. D., Gustafsson, O., Harada, K., Michaels, A. F., van der Loeff'o, M. R., Sarin, M., Steinberg, D. K., and Trull, T.: An assessment of the use of sediment traps for estimating upper ocean particle fluxes, J. Mar. Res., 65(3), 345-416, 2007.

Casotti, R., Landolfi, A., Brunet, C., D’Ortenzio, F., Mangoni, O., Ribera d'Alcalà, M., and Denis, M.: Composition and dynamics of the phytoplankton of the Ionian Sea (eastern Mediterranean), J. Geophys. Res.-Ocean., 108(C9), 8116, doi:10.1029/2002JC001541, 2003.

Conte, M. H., Ralph, N., and Ross, E. H.: Seasonal and interannual variability in deep ocean particle fluxes at the Oceanic Flux Program (OFP)/Bermuda Atlantic Time Series (BATS) site in the western Sargasso Sea near Bermuda, Deep-Sea Res. Pt. II, 48(89), 1471-1505, 2001.

Conte, M. H., Dickey, T. D., Weber, J. C., Johnson, R. J., and Knap, A. H.: Transient physical forcing of pulsed export of bioreactive material to the deep Sargasso Sea, Deep-Sea Res. Pt. I, 50(1011), 1157-1187, 2003.

De La Rocha, C. L. and Passow, U.: Factors influencing the sinking of POC and the efficiency of the biological carbon pump, DeepSea Res. Pt. II, 54(5-7), 639-658, 2007.

Demirov, E. and Pinardi, N.: Simulation of the Mediterranean Sea circulation from 1979 to 1993: Part I. The interannual variability, J. Mar. Syst., 33, 23-50, 2002.

Ediger, D. and Yilmaz, A.: Characteristics of deep chlorophyll maximum in the Northeastern Mediterranean with respect to environmental conditions, J. Mar. Syst., 9(3-4), 291-303, 1996.

Engel, A.: Distribution of transparent exopolymer particles (TEP) in the northeast Atlantic Ocean and their potential significance for aggregation processes, Deep-Sea Res. Pt. I, 51(1), 83-92, 2004.

Francois, R., Honjo, S., Krishfield, R., and Manganini, S.: Factors controlling the flux of organic carbon to the bathypelagic zone of the ocean, Global Biogeochem. Cy., 16(4), 1087, doi:10.1029/2001GB001722, 2002.

Goldthwait, S. A. and Steinberg, D. K.: Elevated biomass of mesozooplankton and enhanced fecal pellet flux in cyclonic and modewater eddies in the Sargasso Sea, Deep-Sea Res. Pt. II, 55(1013), 1360-1377, 2008.

Herut, B., Zohary, T., Krom, M. D., Mantoura, R. F. C., Pitta, P., Psarra, S., Rassoulzadegan, F., Tanaka, T., and Thingstad, T. F.: Response of East Mediterranean surface water to Saharan dust: On-board microcosm experiment and field observations, DeepSea Res. Pt. II, 52(22-23), 3024-3040, 2005.

Honjo, S.: Fluxes of particles to the interior of the open oceans, in:
Particle Flux in the Ocean, edited by: Ittekkot, V., Schäfer, P., Honjo, S., and Depetris, P. J., SCOPE Published by John Wiley \& Sons Ltd, 1996.

Honjo, S., Manganini, S. J., Krishfield, R. A., and Francois, R.: Particulate organic carbon fluxes to the ocean interior and factors controlling the biological pump: A synthesis of global sediment trap programs since 1983, Prog. Oceanogr., 76(3), 217 285, 2008.

Ignatiades, L.: Scaling the trophic status of the Aegean Sea, eastern Mediterranean, J. Sea Res., 54 (1), 51-57, 2005.

Klaas, C. and Archer, D. E.: Association of sinking organic matter with various types of mineral ballast in the deep sea: Implications for the rain ratio, Global Biogeochem. Cy., 16(4), 1116, doi:10.1029/2001GB001765, 2002

Klein, B., Roether, W., Manca, B. B., Bregant, D., Beitzel, V., Kovacevic, V., and Luchetta, A.: The large deep water transient in the Eastern Mediterranean, Deep-Sea Res. Pt. I, 46(3), 371-414, 1999.

Knappertsbusch, M. and Brummer, G.-J. A.: A sediment trap investigation of sinking coccolithophorids in the North-Atlantic, Deep-Sea Res. Pt. I, 42(7), 1083-1109, 1995.

Korres, G., Pinardi, N., and Lascaratos, A.: The ocean response to low-frequency interannual atmospheric variability in the Mediterranean Sea. Part I: sensitivity experiments and energy analysis, J. Climate, 13(4), 705-731, 2000.

Kubilay, N., Nickovic, S., Moulin, C., and Dulac, F.: An illustration of the transport and deposition of mineral dust onto the eastern Mediterranean, Atmos. Environ., 34(8), 1293-1303, 2000.

Lee, C., Armstrong, R. A., Beck, A., Cochran, J. K., Wakeham, S. G., Peterson, M. L., and Miquel, J.-C.: MEDFLUX: Association of organic matter with ballast minerals in sinking particles. American Geophysical Union Fall Meeting, San Francisco (CA, USA), 13-17 December 2004, OS52A-02, 2004.

Lévy, M., Klein, P., and Treguier, A. M.: Impact of sub-mesoscale physics on production and subduction of phytoplankton in an oligotrophic regime, J. Mar. Res., 59(4), 535-565, 2001.

Lutz, M., Dunbar, R., and Caldeira, K.: Regional variability in the vertical flux of particulate organic carbon in the ocean interior, Global Biogeochem. Cy., 16(3), 1037, doi:10.1029/2000GB001383, 2002.

Lutz, M. J., Caldeira, K., Dunbar, R. B., and Behrenfeld, M. J.: Seasonal rhythms of net primary production and particulate organic carbon flux to depth describe the efficiency of biological pump in the global ocean, J. Geophys. Res.-Ocean., 112(C10), C10011, doi:10.1029/2006JC003706, 2007.

Madec, G., Delecluse, P., Imbard, M., and Lévy, C.: OPA version 8.1 Ocean General Circulation Model reference manual, Technical Report, Note 11, LODYC/IPSL, Paris, France, 91 pp., 1998.

Mahadevan, A.: Modeling vertical motion at ocean fronts: Are nonhydrostatic effects relevant at submesoscales?, Ocean Model, 14(3-4), 222-240, 2006.

Malanotte-Rizzoli, P., Manca, B. B., D’Alcalà, M. R., Theocharis, A., Bergamasco, A., Bregant, D., Budillon, G., Civitarese, G., Georgopoulos, D., Michelato, A., Sansone, E., Scarazzato, P., and Souvermezoglou, E.: A synthesis of the Ionian Sea hydrography, circulation and water mass pathways during POEM Phase I, Prog. Oceanogr., 39(3), 153-204, 1997.

Malanotte-Rizzoli, P., Manca, B. B., Ribera d'Alcala, M., Theocharis, A., Brenner, S., Budillon, G., and Oszoy, E.: The 
Eastern Mediterranean in the 80s and in the 90s: the big transition in the intermediate and deep circulations, Dynam. Atmos. Ocean., 29(2-4), 365-395, 1999.

Malinverno, E., Ziveri, P., and Corselli, C.: Coccolithophorid distribution in the Ionian Sea and its relationship to eastern Mediterranean circulation during late fall to early winter 1997, J. Geophys. Res.-Ocean., 108(C9), 8115, doi:10.1029/2002JC001346, 2003.

Manca, B. B., Budillon, G., Scarazzato, P., and Ursella, L.: Evolution of dynamics in the eastern Mediterranean affecting water mass structures and properties in the Ionian and Adriatic Seas, J. Geophys. Res.-Ocean., 108(C9), 8102, doi:10.1029//2002JC001664, 2003.

Markaki, Z., Oikonomou, K., Kocak, M., Kouvarakis, G., Chaniotaki, A., Kubilay, N., and Mihalopoulos, N.: Atmospheric deposition of inorganic phosphorus in the Levantine Basin, eastern Mediterranean: Spatial and temporal variability and its role in seawater productivity, Limnol. Oceanogr., 48(4), 1557-1568, 2003.

Mazzocchi, M. G., Nervegna, D., D’Elia, G., Di Capua, I., Aguzzi, L., and Boldrin, A.: Spring mesozooplankton communities in the epipelagic Ionian Sea in relation to the Eastern Mediterranean Transient, J. Geophys. Res.-Ocean., 108, 8114, doi:10.1029/2002JC001640, 2003.

McGillicuddy, D. J., Johnson, R., Siegel, D. A., Michaels, A. F., Bates, N. R., and Knap, A. H.: Mesoscale variations of biogeochemical properties in the Sargasso Sea, J. Geophys. Res.Ocean., 104(C6), 13381-13394, 1999.

McGillicuddy, D. J., Kosnyrev, V. K., Ryan, J. P., and Yoder, J. A.: Covariation of mesoscale ocean color and sea-surface temperature patterns in the Sargasso Sea, Deep-Sea Res. Pt. II, 48(8-9), 1823-1836, 2001.

Molcard, A., Pinardi, N., Iskandarani, M., Haidvogel, D.B.: Wind driven general circulation of the Mediterranean Sea simulated with a Spectral Element Ocean Model, Dynam. Atmos. Ocean., 35(2), 97-130, 2002.

Pacanowski, R. C. and Gnanadesikan, A.: Transient response in a z-level ocean model that resolves topography with partial cells, Mon. Weather Rev., 126(12), 3248-3270, 1998.

Pinardi, N. and Navarra, A.: Baroclinic wind adjustment processes in the Mediterranean Sea, Deep-Sea Res. Pt. II, 40(6), 12991326, 1993.

Pinardi, N. and Masetti, E.: Variability of the large scale general circulation of the Mediterranean Sea from observations and modelling: a review, Palaeogeogr. Palaeocl., 158(3-4), 153-174, 2000.

Pinardi, N., Arneri, E., Crise, A., Ravaioli, M., and Zavatarelli, M.: The physical, sedimentary and ecological structure and variability of shelf areas in the Mediterranean Sea, in: The Sea, Vol. 14, Harvard University Press, 1243-1330, 2005.

Pond, S. and Pickard, G. L.: Introductory Dynamical Oceanography, 2nd edition, Elsevier Butterworth-Heinemann, 349 pp., 1983.

Robinson, A. R., Hecht, A., Pinardi, N., Bishop, J., Leslie, W. G., Rosentroub, Z., Mariano, A. J., and Brenner, S.: Small synoptic mesoscale eddies and energetic variability of the Eastern Levantine Basin, Nature, 327(6118), 131-134, 1987.
Robinson, A. R., Sellschopp, J., Warn-Varnas, A., Leslie, W. G., Lozano, C. J., Haley, P. J., Anderson, L. A., and Lermusiaux, P. F. J.: The Atlantic Ionian Stream, J. Mar. Syst., 20(1-4), 129156, 1999.

Sarmiento, J. L. and Gruber, N.: Ocean Biogeochemical Dynamics, Princeton University Press, Princeton, NJ, USA, 318-358, 2006.

Sciarra, R., Boehm, E., D'Acunzio, E., and Santoleri, R.: The large scale observing system component of ADRICOSM: the satellite system, Acta Adriatica, 47, 51-64, 2006.

Siegel, D. A., Fields, E., and Buesseler, K. O.: A bottom-up view of the biological pump: Modeling source funnels above ocean sediment traps, Deep-Sea Res. Pt. I, 55(1), 108-127, 2008.

Stemmann, L., Gorsky, G., Marty, J.C., Picheral, M., and Miquel, J. C.: Four-year study of large-particle vertical distribution (0$1000 \mathrm{~m}$ ) in the NW Mediterranean Sea in relation to hydrology, phytoplankton, and vertical flux, Deep-Sea Res. Pt. II, 49(11), 2143-2162, 2002.

Sweeney, E. N., McGillicuddy, D. J., and Buesseler, K. O.: Biogeochemical impacts due to mesoscale eddy activity in the Sargasso Sea as measured at the Bermuda Atlantic Time-series Study (BATS), Deep-Sea Res. Pt. II, 50(22-26), 3017-3039, 2003.

Tonani, M., Pinardi, N., Dobricic, S., Pujol, I., and Fratianni, C.: A high-resolution free-surface model of the Mediterranean Sea, Ocean Science, 4(1), 1-14, 2008.

Trull, T. W., Bray, S. G., Buesseler, K. O., Lamborg, C. H., Manganini, S., Moy, C., and Valdes, J.: In situ measurement of mesopelagic particle sinking rates and the control of carbon transfer to the ocean interior during the Vertical Flux in the Global Ocean (VERTIGO) voyages in the North Pacific, DeepSea Res. Pt. II, 55(14-15), 1684-1695, 2008.

Turner, J. T.: Zooplankton fecal pellets, marine snow and sinking phytoplankton blooms, Aquat. Microb. Ecol., 27(1), 57-102, 2002.

Volpe, G., Banzon, V. F., Evans, R. H., and Mariano, A. J.: Satellite observations of the impact of dust in a low nutrient low chlorophyll region: fertilization or artifact?, submitted, 2009.

Yoon, W. D., Marty, J. C., Sylvain, D., and Nival, P.: Degradation of faecal pellets in Pegea confoederata (Salpidae, Thaliacea) and its implication in the vertical flux of organic matter, J. Exp. Mar. Biol. Ecol., 203(2), 147-177, 1996.

Yoon, W. D., Kim, S. K., and Han, K. N.: Morphology and sinking velocities of fecal pellets of copepod, molluscan, euphasiid, and salp taxa in the northeastern tropical Atlantic, Mar. Biol., 139, 923-928, 2001.

Ziveri, P., Rutten, A., de Lange, G. J., Thomson, J., and Corselli, C.: Present-day coccolith fluxes recorded in central eastern Mediterranean sediment traps and surface sediments, Palaeogeogr. Palaeocl., 158(3-4), 175-195, 2000.

Zuñiga, D., Calafat, A., Heussner, S., Miserocchi, S., SanchezVidal, A., Garcia-Orellana, J., Canals, M., Sanchez-Cabeza, J. A., Carbonne, J., Delsaut, N., and Saragoni, G.: Compositional and temporal evolution of particle fluxes in the open AlgeroBalearic basin (Western Mediterranean), J. Mar. Syst., 70(1-2), 196-214, 2008. 